\title{
Climatology of Linear Mesoscale Convective System Morphology in the United States Based on the Random-Forests Method
}

\author{
Wenjun Cui, ${ }^{\mathrm{a}}$ Xiquan Dong, ${ }^{\mathrm{a}}$ BAiKe XI, ${ }^{\mathrm{a}}$ And Zhe FenG ${ }^{\mathrm{b}}$ \\ ${ }^{a}$ Department of Hydrology and Atmospheric Sciences, The University of Arizona, Tucson, Arizona \\ ${ }^{\mathrm{b}}$ Pacific Northwest National Laboratory, Richland, Washington
}

(Manuscript received 9 November 2020, in final form 7 April 2021)

\begin{abstract}
This study uses machine-learning methods, specifically the random-forests (RF) method, on a radar-based mesoscale convective system (MCS) tracking dataset to classify the five types of linear MCS morphology in the contiguous United States during the period 2004-16. The algorithm is trained using radar- and satellite-derived spatial and morphological parameters, along with reanalysis environmental information from a 5-yr manually identified nonlinear mode and five linear MCS modes. The algorithm is then used to automate the classification of linear MCSs over 8 years with high accuracy, providing a systematic, long-term climatology of linear MCSs. Results reveal that nearly $40 \%$ of MCSs are classified as linear MCSs, of which one-half of the linear events belong to the type of system having a leading convective line. The occurrence of linear MCSs shows large annual and seasonal variations. On average, 113 linear MCSs occur annually during the warm season (March-October), with most of these events clustered from May through August in the central eastern Great Plains. MCS characteristics, including duration, propagation speed, orientation, and system cloud size, have large variability among the different linear modes. The systems having a trailing convective line and the systems having a back-building area of convection typically move more slowly and have higher precipitation rate, and thus they have higher potential for producing extreme rainfall and flash flooding. Analysis of the environmental conditions associated with linear MCSs show that the storm-relative flow is of most importance in determining the organization mode of linear MCSs.
\end{abstract}

KEYWORDS: Convective storms; Hydrometeorology; Mesoscale systems; Classification; Machine learning

\section{Introduction}

Mesoscale convective systems (MCSs) are the largest cloud systems and develop from upscale growth and/or aggregation of cumulonimbus clouds (Houze 2004, 2019). In the central Great Plains of the United States, one of the most active places in the midlatitudes for MCSs activity, between roughly $30 \%$ and $70 \%$ of the total warm-season precipitation is produced by these systems (Cui et al. 2020a; Fritsch et al. 1986; Nesbitt et al. 2006). In addition to the MCSs' significant role in the hydrological cycle, they are often responsible for the production of severe weather hazards, including hail, severe wind, tornados, and flooding (Houze 2004; Jirak and Cotton 2007; Schumacher and Johnson 2005, hereinafter SJ05).

Previous studies (Gallus et al. 2008; Guillot et al. 2008; Pettet and Johnson 2003) have found that the type and extent of severe weather produced by MCSs is strongly correlated with specific convective morphology. MCSs consist of both stratiform and convective regions (Houze 2004). The convective cells within an MCS can sometimes be arranged semi-independently or appear to have linear organization. The former type of MCS is called nonlinear, and the latter is called linear. In general, linear systems are more often associated with all types of severe weather hazards than nonlinear systems, with wind and flooding threats being of particular note (Gallus et al. 2008). On the basis of manual identification of MCS morphology from radar images, three types of linear MCSs are found to have higher chances in producing extreme rainfall (flash flood) events-that is,

Corresponding author: Xiquan Dong, xdong@arizona.edu systems having leading stratiform (LS), trailing line and adjoining stratiform (TL/AS), and back-building or a quasistationary area of convection that produces a stratiform region downstream (abbreviated BB) (Parker and Johnson 2000, hereinafter PJ00; SJ05). Therefore, classification of linear MCS morphology is important for determining the relationship between MCS morphology and its hydrological impact and improving the understanding of dynamical processes that are responsible for the production of certain MCS morphologies.

Numerous studies (Cui et al. 2019; Parker and Johnson 2004; Peters and Schumacher 2016; Schumacher and Johnson 2006; Wang et al. 2014) have investigated the environmental conditions, dynamical processes, and cloud and precipitation characteristics associated with MCSs according to the convective morphology mentioned above through both observational and modeling efforts. From the observational perspective, the determination of a MCS's morphology largely relies on the manual analysis of radar reflectivity images. This method, however, significantly limits the amount of data that can be feasibly analyzed in a study by requiring a tremendous amount of time to obtain a large amount of data. For example, a total number of 88,116 , and 218 linear MCS events were analyzed in PJ00, SJ05, and Gallus et al. (2008), respectively. Because of the limitation in manual identification methods, many promising areas of research (such as probabilistic forecasts of morphology using large ensembles, determination of convective morphology in relation to severe weather hazards from long-term datasets, and climatology of convective modes) are prohibited if they are reliant upon manual procedures. Therefore, an automated algorithm for MCS morphology classification should be developed. 
In recent years, the application of artificial intelligence (AI) techniques, such as machine learning (ML), in meteorological studies has become more frequent (Ashley et al. 2019; Haberlie and Ashley 2018; Gagne et al. 2017, 2019; Herman and Schumacher 2018). ML utilizes statistical methods that enable machines or computers to learn iteratively when presented with more data or experiences (McGovern et al. 2017). The efforts in developing automated procedures for MCS morphology classification based on ML methods can be traced back to the work of Baldwin et al. (2005). A classifier that is based on the nearest-neighbor approach was developed in their study to first separate large precipitating systems into convective and nonconvective classes and then move down to the next-level classifier to further divide the convective into linear and cellular subsets or nonconvective to stratiform subsets. The classifier was built on rainfall $R$ intensity and morphological parameters and has an accuracy of $85 \%$. Gagne et al. (2009) utilized a decision-tree classifier to classify convective systems into six morphological modes, with three cellular classes and three linear classes, from morphological, radar reflectivity, and wind parameters. The algorithm has an overall accuracy of $92 \%$ for cellular and linear separation and $70 \%$ for specified mode classification. In more recent work, Thielen (2018) evaluated and compared several ML techniques for detailed classification of the nine convective modes defined in Gallus et al. (2008). Thielen found that an ensemble of decision tree classifiers utilizing a large set of input parameters performed the best at detailed classification of convective morphology with an overall accuracy of $50 \%$. The model accuracy shows large variability when specified to individual modes, however.

The purpose of this study is to employ ML techniques, specifically the random-forests (RF) method, to develop an automated MCS morphology classification algorithm that is able to separate MCSs into a nonlinear class and five linear classes identified by PJ00 [trailing stratiform (TS), parallel stratiform (PS), and LS] and SJ05 (BB and TL/AS) with sufficient accuracy (i.e., $>80 \%$ accuracy) that the classifier is able to be applied to climatological studies of linear MCSs and to further assess their hydrological impacts. The results from previous studies suggest that the choice of training parameters is of particular importance in constructing the classification system and eventually affects the prediction accuracy. Therefore, a 13-yr MCS dataset stretching from 2004 to 2016 over the central and eastern United States is used for classification algorithm development, evaluation, and implementation. The MCSs' identification and tracking in this study were based upon high-quality satellite, radar, and precipitation datasets, as well as data from highspatiotemporal-resolution reanalysis. The climatology of linear MCSs constructed through the automated technique in this study will provide an overview of the spatiotemporal characteristics of these events across the continental United States. This study will shed light on improving the understanding of the environmental factors that are responsible for the formation of certain linear types and how these factors may affect the MCS properties, particularly the precipitation properties as these systems are often associated with extreme rainfall and flood events.

\section{MCS identification and tracking}

\section{a. Observation datasets}

The 13-yr high-resolution MCS tracking dataset over the United States is obtained from the U.S. Department of Energy (DOE) Atmospheric Radiation Measurement (ARM) data archive (https://doi.org/10.5439/1571643). MCSs are identified using three long-term high-resolution observational datasets: the globally merged infrared (IR) brightness temperature $T_{b}$ data produced by NCEP/Climate Prediction Center (CPC), the mosaicked Next Generation Weather Radars (NEXRAD) radar reflectivity from GridRad, and the Stage-IV precipitation product produced by the River Forecast Centers. The halfhourly globally merged IR dataset (Janowiak et al. 2001) is available at $4-\mathrm{km}$ spatial resolution and is used to identify the deep convective clouds associated with MCSs. The 3D characteristics of MCSs are provided by the GridRad radar reflectivity $Z$ data. The hourly radar reflectivity data are produced by merging radar reflectivity data from a network of 125 National Weather Service NEXRAD WSR-88D instruments and rescaling onto a common grid (Bowman and Homeyer 2017). The GridRad data cover the contiguous United States (CONUS) and have $0.02^{\circ} \times 0.02^{\circ}$ spatial and $1-\mathrm{km}$ vertical resolutions. The precipitation rate and amount associated with MCSs are obtained using the hourly precipitation produced by the Stage-IV product. The hourly Stage-IV product utilizes precipitation estimates computed with a $Z-R$ relationship from all NEXRAD radars and combines about 5500 hourly rain gauge measurements to produce precipitation analysis at $4-\mathrm{km}$ resolution over the CONUS (Lin and Mitchell 2005). Because of the beam blockage issue in radar observations in the western United States, only MCSs occurring in the central and eastern United States are investigated in this study. To create a synthesized dataset for identifying and tracking MCSs, the GridRad and Stage-IV data are interpolated to match the satellite IR 4-km grid using the Earth System Modeling Framework (ESMF) regridding software (https:/www.ncl.ucar.edu/Applications/ ESMF.shtml). The detailed regridding process can be found in Feng et al. (2019).

\section{b. Tracking algorithm}

The three datasets have an overlap period from 2004 to 2016. MCSs occurring east of the Rocky Mountains during March-October within a domain bounded by $25^{\circ}-50^{\circ} \mathrm{N}$ and $110^{\circ}-70^{\circ} \mathrm{W}$ during this $13-\mathrm{yr}$ period are identified and tracked using a recently developed tracking algorithm called the Flexible Object Tracker (FLEXTRKR; Feng et al. 2018). The method first identifies and tracks large cold cloud systems (CCSs; $T_{b}<241 \mathrm{~K}$ ) associated with deep convection using satellite $T_{b}$ data, and subsequently uses the 3D radar reflectivity data to identify large precipitation features (PFs: contiguous radar echoes at 2-km height larger than $17 \mathrm{dBZ}$ ) that contain intense convection. A CCS will be defined as an MCS when the cold cloud shield area exceeds $6 \times 10^{4} \mathrm{~km}^{2}$, containing a PF with major axis length $>100 \mathrm{~km}$ and convective feature with radar reflectivity $>45 \mathrm{dBZ}$ at any vertical level, and having a lifetime longer than $6 \mathrm{~h}$ (Feng et al. 2019). 
TABLE 1. A list of parameters, by category, used in the random-forest classifier.

\begin{tabular}{|c|c|c|}
\hline Parameter & Definition & $\begin{array}{c}\text { No. of input } \\
\text { values }\end{array}$ \\
\hline \multicolumn{3}{|c|}{ Statistical variables (37) } \\
\hline $\mathrm{PF}$ rain rate & Mean rain rate of precipitation features $(\mathrm{PF})$ at each tracked time $\left(\mathrm{mm} \mathrm{h}^{-1}\right)$ & 3 \\
\hline PF SR rain rate & Mean stratiform region (SR) rain rate of precipitation features at each tracked time $\left(\mathrm{mm} \mathrm{h}^{-1}\right)$ & 3 \\
\hline $\mathrm{PF} C \mathrm{C}$ rain rate & Mean convective core $(\mathrm{CC})$ rain rate of precipitation features at each tracked time $\left(\mathrm{mm} \mathrm{h}^{-1}\right)$ & 3 \\
\hline Cold cloud shield area & Area of cold cloud shield at each tracked time $\left(\mathrm{km}^{2}\right)$ & 3 \\
\hline SR area & Area of SR from SL3D classification at each tracked time $\left(\mathrm{km}^{2}\right)$ & 3 \\
\hline $\mathrm{CC}$ area & Area of CC from SL3D classification at each tracked time $\left(\mathrm{km}^{2}\right)$ & 3 \\
\hline Major axis length & Major axis length of cloud at each tracked time $(\mathrm{km})$ & 3 \\
\hline Major CC axis length & Convective core major axis length of the largest $\mathrm{PF}$ at each tracked time $(\mathrm{km})$ & 3 \\
\hline Speed & Propagation speed of MCS $\left(\mathrm{m} \mathrm{s}^{-1}\right)$ & 3 \\
\hline Eccentricity & Eccentricity of the ellipse best fitting the system region & 3 \\
\hline $45-\mathrm{dB} Z$ area & Area with column maximum reflectivity $\geq 45 \mathrm{dBZ}$ at each tracked time $\left(\mathrm{km}^{2}\right)$ & 2 \\
\hline 40-dBZ height & Mean convective $40-\mathrm{dB} Z$ echo-top height at each tracked time $(\mathrm{km})$ & 2 \\
\hline Lifetime & Lifetime of tracked MCS (h) & 1 \\
\hline Travel distance & $\begin{array}{l}\text { The distance in degrees of longitude/latitude that the tracked MCS traveled from the initiation } \\
\text { location to the dissipation location }\left(^{\circ}\right)\end{array}$ & 1 \\
\hline Travel direction & $\begin{array}{l}\text { The angle from the tracked MCS initiation location to dissipation location counterclockwise } \\
\text { from due south }\left({ }^{\circ}\right)\end{array}$ & 1 \\
\hline \multicolumn{3}{|c|}{ Linear properties (16) } \\
\hline Mean-square error (MSE) & $\begin{array}{l}\text { The mean-square error between the fitted and original convective pixel locations at the } \\
\text { given time }\end{array}$ & 1 \\
\hline Correlation coef $(r)$ & The correlation coefficient between the fitted and original latitude values at the given time & 1 \\
\hline Coef & The coefficient of fitted line & 1 \\
\hline No. of convective pixels & No. of convective pixels based on SL3D classification at the given time & 1 \\
\hline$\Delta x$ & $\begin{array}{l}\text { The horizontal distance in degrees of longitude between the CC and SR centers at the } \\
\text { given time }\left({ }^{\circ}\right)\end{array}$ & 1 \\
\hline$\Delta y$ & $\begin{array}{l}\text { The meridional distance in degrees of latitude between the CC and SR centers at the } \\
\text { given time }\left({ }^{\circ}\right)\end{array}$ & 1 \\
\hline SR area & Area of SR from SL3D classification at the given time $\left(\mathrm{km}^{2}\right)$ & 1 \\
\hline $\mathrm{CC}$ area & Area of CC from SL3D classification at the given time $\left(\mathrm{km}^{2}\right)$ & 1 \\
\hline Rain rate & Mean rain rate at the given time $\left(\mathrm{mm} \mathrm{h}^{-1}\right)$ & 1 \\
\hline $\mathrm{SR}$ rain rate & Mean stratiform rain rate at the given time $\left(\mathrm{mm} \mathrm{h}^{-1}\right)$ & 1 \\
\hline $\mathrm{CC}$ rain rate & Mean convective rain rate at the given time $\left(\mathrm{mm} \mathrm{h}^{-1}\right)$ & 1 \\
\hline Eccentricity & Eccentricity of the ellipse best fitting the system region at the given time & 1 \\
\hline $45-\mathrm{dB} Z$ area & Area with column maximum reflectivity $\geq 45 \mathrm{dBZ}$ at the given time $\left(\mathrm{km}^{2}\right)$ & 1 \\
\hline 40-dBZ height & Mean convective $40-\mathrm{dB} Z$ echo-top height at the given time $(\mathrm{km})$ & 1 \\
\hline Major axis length & Major axis length of cloud at the given time $(\mathrm{km})$ & 1 \\
\hline Major CC axis length & Convective core major axis length of the largest $\mathrm{PF}$ at the given time $(\mathrm{km})$ & 1 \\
\hline \multicolumn{3}{|c|}{ Wind properties $(8)$} \\
\hline$U$ wind & 925-, 500-, and 200-hPa zonal wind speeds at MCS initiation time and location, respectively & 3 \\
\hline$V$ wind & $\begin{array}{l}925-, 500-, \text { and } 200-\mathrm{hPa} \text { meridional wind speeds at MCS initiation time and location, } \\
\text { respectively }\end{array}$ & 3 \\
\hline $\begin{array}{l}\text { Mid- to low-level directional } \\
\text { wind shear }\end{array}$ & $\begin{array}{l}\text { Directional difference between } 500-\text { and } 925-\mathrm{hPa} \text { wind }\left({ }^{\circ}\right) \text { at } \mathrm{MCS} \text { initiation and maximum } \\
\text { cloud size times and locations, respectively }\end{array}$ & 2 \\
\hline
\end{tabular}

FLEXTRKR classifies the tracked system into convective, stratiform, and anvil components using the storm labeling in three dimensions (SL3D; Starzec et al. 2017) algorithm. FLEXTRKR also provides many statistical properties including the cloud and $\mathrm{PF}$ areas, mean precipitation rate, major axis length, eccentricity, and duration. These properties, as well as the convective and stratiform properties of each tracked MCS, are used as input variables for training the random-forest classifiers, which is further discussed in section $3 \mathrm{a}$.

\section{Model development and evaluation}

\section{a. Variable selection and calculation}

Table 1 summarizes the variables designed to potentially differentiate the nonlinear (NL) and five linear MCS modes described in PJ00 and SJ05. The variables are divided into three categories. The variables under the "statistical variables" category are directly outputted from FLEXTRKR algorithm. The number of input values equaling 3 indicates that the mean, maximum, and minimum values of that variable during the 
MCS's lifetime are used for training the classifier; equaling 2 indicates that the minimum value is excluded because the variable contains too many zero values (i.e., the radar reflectivity of a MCS is often below $30 \mathrm{~dB} Z$ during the dissipation stage, and therefore the minimum values of $45-\mathrm{dB} Z$ area and 40-dB $Z$ height are equal to zero) and might not be helpful for distinguishing different modes. Some of the variables, such as rain rate and CCS properties (lifetime, speed, eccentricity, and major axis length), seem less relevant for identifying linearity of convective feature associated with an MCS. These variables are included here because they are different among different modes as found in previous studies. For instance, TS systems generally have longer lifetime than LS and PS systems (PJ00), and higher precipitation rates are expected in LS, BB, and TL/AS systems. Therefore, these variables could be helpful in differentiating between different linear modes.

The variables under the "linear property" category are calculated and extracted when the linearity of that MCS is the most apparent. This is determined by applying a linear regression to the SL3D identified convective pixels to first obtain a fitted convective line and then to calculate the correlation coefficient $r$ between the fitted and original latitude values, as well as the mean squared error (MSE) of the line during an MCS's lifetime. The calculated $r$ and MSE are arranged in descending order based on the number of convective pixels, as a mature line tends to develop when the convective activity of a system reaches its maximum (PJ00; Cui et al. 2019). When $r$ exceeds $0.6, \sigma$ is less than 0.5 , and the system contains more than 120 convective pixels, the variables from that time step will be used. These threshold values were determined by several sensitivity tests to ensure both the linear and convective features of the system can be captured. If the system does not meet these criteria, the variables at the time when the largest convective feature reaches maximum area will be used.

The variables under the "wind property" category are obtained and computed from ERA5 reanalysis. ERA5 reanalysis is developed as the fifth generation of European Centre for Medium-Range Weather Forecasts (ECMWF) climate reanalysis, covering the time period from 1950 to five days behind real time (Hersbach et al. 2020). The atmospheric pressure level analysis from ERA5 is used in this study. The analysis fields have a spatial resolution of $0.25^{\circ} \times 0.25^{\circ}$, and temporal resolution of $1 \mathrm{~h}$, covering 37 pressure levels from 1000 to 1 $\mathrm{hPa}$. The wind speeds at 925,500 , and $200 \mathrm{hPa}$, as well as the mid-to-low (500-925 hPa) and high-to-mid (200-500 hPa) level directional wind shear, are obtained from ERA5 at the MCS initiation and genesis times and locations (the nearest grid point in ERA5 to the MCS central point). MCS initiation is defined as the first hour a CCS is detected in the satellite $T_{b}$ data of the tracked system. MCS genesis occurs during the first hour after the major axis length of a convective feature (contiguous convective pixels) exceeds $100 \mathrm{~km}$ (Feng et al. 2019). This is the time when the tracked system meets the MCS size criteria defined in Houze (2004). These variables are selected as predictors because the stratiform arrangement associated with a MCS is primarily determined by the mid- and upper- tropospheric environmental flows, which are significantly different among different modes (PJ00, SJ05). It is noteworthy that the identifications of MCS initiation and genesis in this study are based on the satellite and radar observations of the tracked cloud system and have not considered the dynamical and physical mechanisms involved during these processes.

\section{b. Manual classification}

To complete the preparation of training and testing data for the classifiers, the radar reflectivity images of tracked MCSs during 2004, 2005, and 2014-16 are manually labeled according to the five linear modes defined in PJ00 and SJ05. For each MCS, radar images during its lifetime have all been examined to determine the dominant mode of that system, and only one mode is assigned to each MCS. The systems that moved outside the study domain or occurred with bad radar coverages are discarded. Figure 1 shows the radar and SL3D images of the manually labeled MCS in each mode. These images were selected at the times when the linearity of the system is the most apparent, following the steps described in section 3a. During this 5-yr period, $1148 \mathrm{MCSs}$ have been manually classified into $684 \mathrm{NL}$ cases, 260 TS cases, 30 LS cases, 56 PS cases, 57 BB cases, and $61 \mathrm{TL} / \mathrm{AS}$ cases.

\section{c. Model construction and statistical evaluation}

The RFs classifier from scikit-learn software (Pedregosa et al. 2011) is used for classifying the modes of MCSs in this study. Instead of using a single classifier to differentiate all six modes, an ensemble classifier combining three individual classifiers have been developed. As illustrated in Fig. 2a, classifier I serves to distinguish between the NL and linear modes; classifier II separates the TS mode from the other four linear modes; and classifier III is used to distinguish between the LS, PS, BB, and TL/AS modes. The manually identified MCSs are split into three subsets of training, validation, and testing, and the detailed sample numbers associated with each classifier are summarized in Table 2. Each initial classifier is trained individually with the full set of predictor variables (61 variables). To avoid the imbalanced distribution in predicted class resulting from the imbalanced distribution of training class, the training data are adjusted so that the number of samples falling into each mode will be equally distributed. For example, the NL category has a larger sample size than all linear categories combined. Therefore, the NL category is slightly undersampled ( $70 \%$ of the total NL population) in order to become more balanced with the linear categories $(80 \%$ of the total linear population) for training the classifier I. It is noted that the model accuracy is independent from the selection of training, validation, and testing sets. The model performance is examined based on randomly generated input sets, and their overall accuracies are similar.

Next, to maximize model performance and reduce overfitting, tuning on model hyperparameters and testing different combinations of predictor variables are performed. This process is accomplished by generating new models from the same training set as the initial classifiers, but with different choices of hyperparameters and predictor variables. The selected hyperparameters include the number of estimators, maximum depth 
(a1) TS Ze at $2016061101 Z$

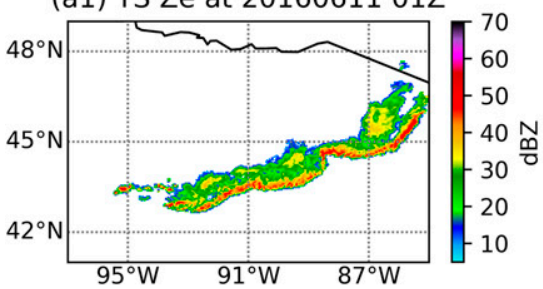

(b1) LS Ze at $2015070204 Z$

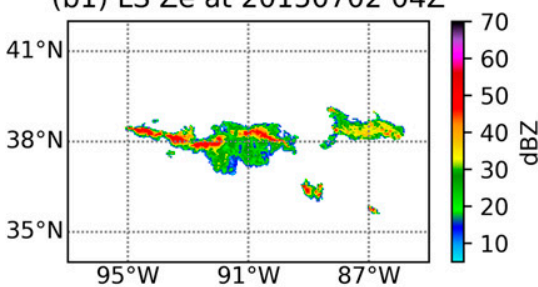

(c1) PS Ze at $2016100501 Z$

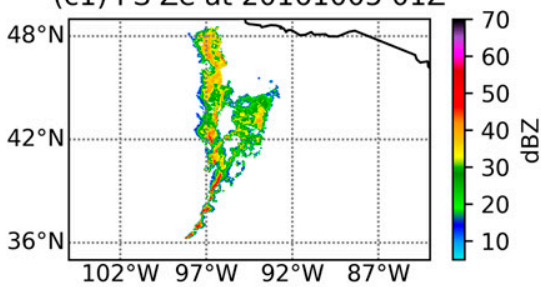

(d1) BB Ze at $2016052700 Z$

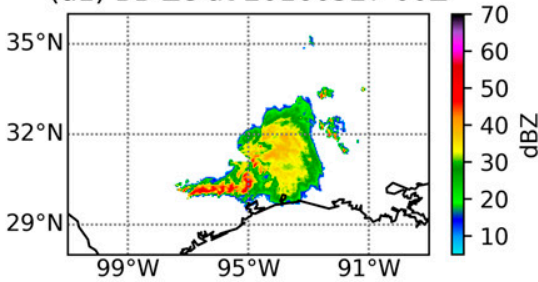

(e1) TL/AS Ze at $2016062308 Z$

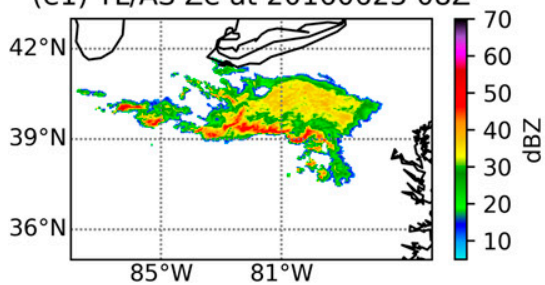

(a2) TS SL3D at $2016061101 Z$

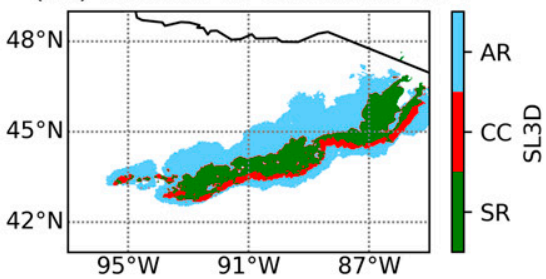

(b2) LS SL3D at $2015070204 Z$

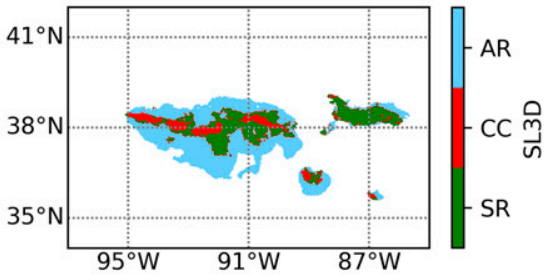

(c2) PS SL3D at $2016100501 Z$

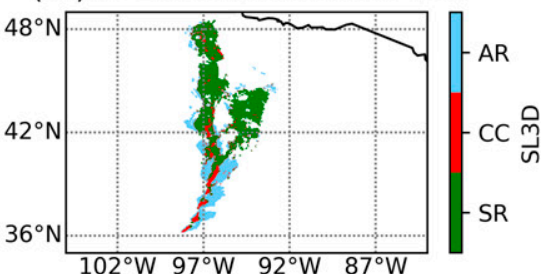

(d2) BB SL3D at $2016052700 Z$

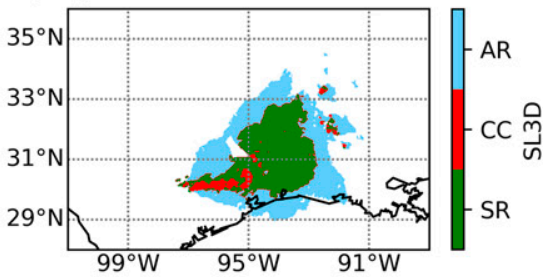

(e2) TL/AS SL3D at $2016062308 Z$

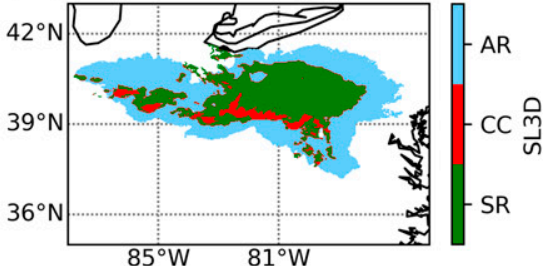

FIG. 1. The (left) radar reflectivity and (right) SL3D classifications of the five linear MCS modes used in this study; SR represents stratiform rain region, $\mathrm{CC}$ represents convective core region, and AR represents anvil region. The (a1),(a2) trailing stratiform (TS), (b1),(b2) leading stratiform (LS), and (c1),(c2) parallel stratiform (PS) MCSs were defined in PJ00; the (d1),(d2) back-building (BB) and (e1),(e2) trailing line and adjoining stratiform (TL/AS) MCSs were defined in SJ05.

of the tree, and randomness of the bootstrapping of the samples used in building trees (bootstraps are used for all models). Four different combinations of predictors are examined here. For instance, the first set consists of all 61 variables and the second to fourth sets exclude the minimum, maximum, and both maximum and minimum values, respectively, of the variables under the statistical category $(51,49$, and 39 variables) because they are less relevant to the linear characteristics of a 


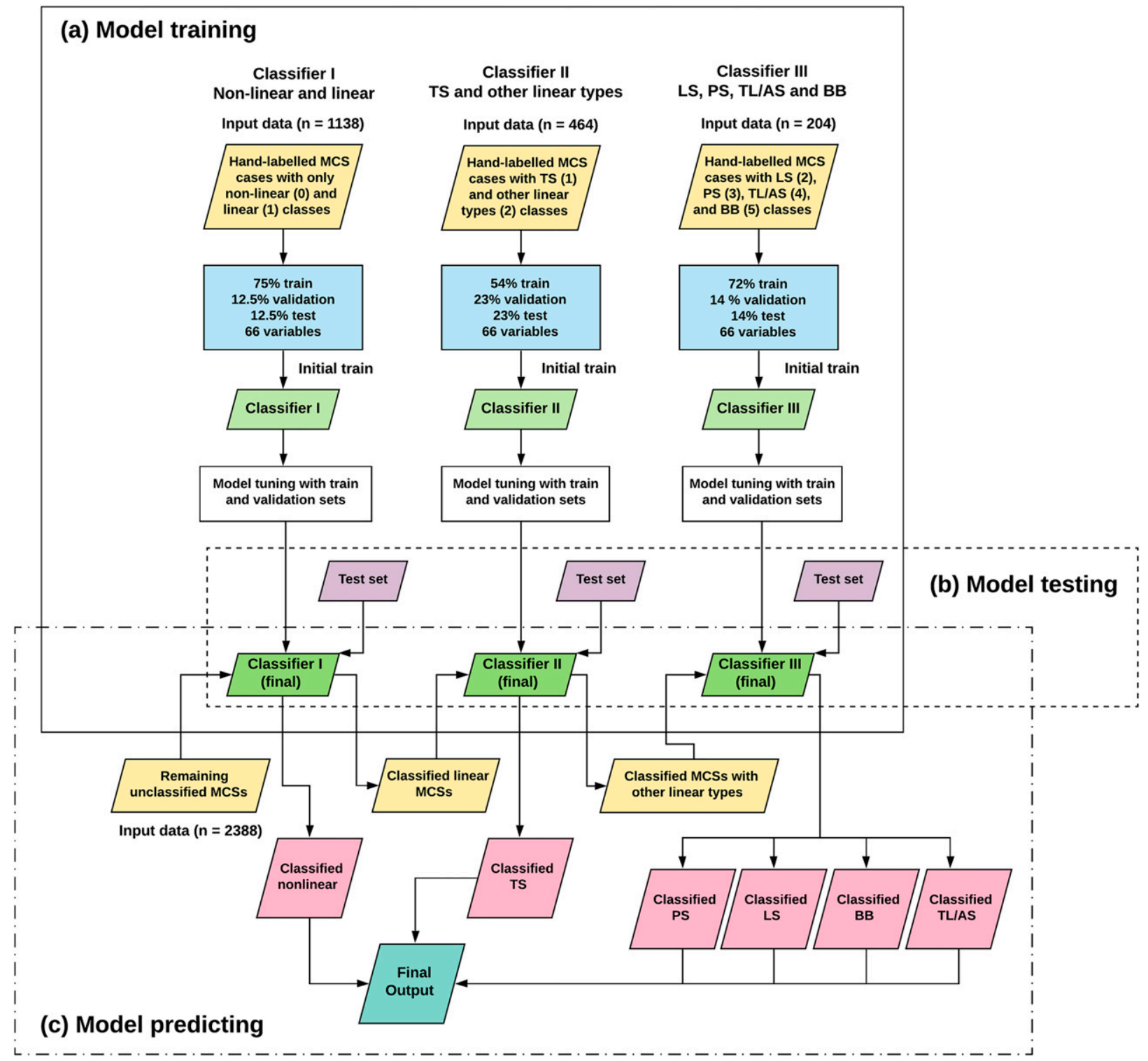

FIG. 2. A schematic flowchart showing (a) the procedures for training the model, (b) model validation, and (c) application of the model to automatically classify the MCS organization mode.

system. The performances of these models are evaluated by the weighted precision and recall scores when applied to the validation set. The precision score is defined as

$$
\text { precision }=\frac{T_{p}}{T_{p}+F_{p}},
$$

and recall score is defined as

$$
\text { recall }=\frac{T_{p}}{T_{p}+F_{n}} .
$$

The terms $T_{p}, F_{p}$, and $F_{n}$ are the number of true positives, false positives, and false negatives for a given mode, respectively. In general, precision refers to the proportion of correct predictions to the total predictions of a given mode and recall refers to the proportion of correct predictions to the actual number (true) of systems of a given mode. The model with the best performance using the validation set will be evaluated on the test set to obtain the final accuracy. The maximum depth, number of estimators, and randomness of the bootstrap are 11, 120, and 3 for final classifier I; 10, 50, and 5 for final classifier II; and 5, 120, and 0 for final classifier III, respectively. For the choice of predictor variables, classifiers I-III use the third set, the second set, and the fourth set of variable combinations, respectively.

For implementation of the ensemble classifier (Fig. 2c), the systems that are labeled as linear mode from classifier I will be passed down to the next level classifier to determine whether 


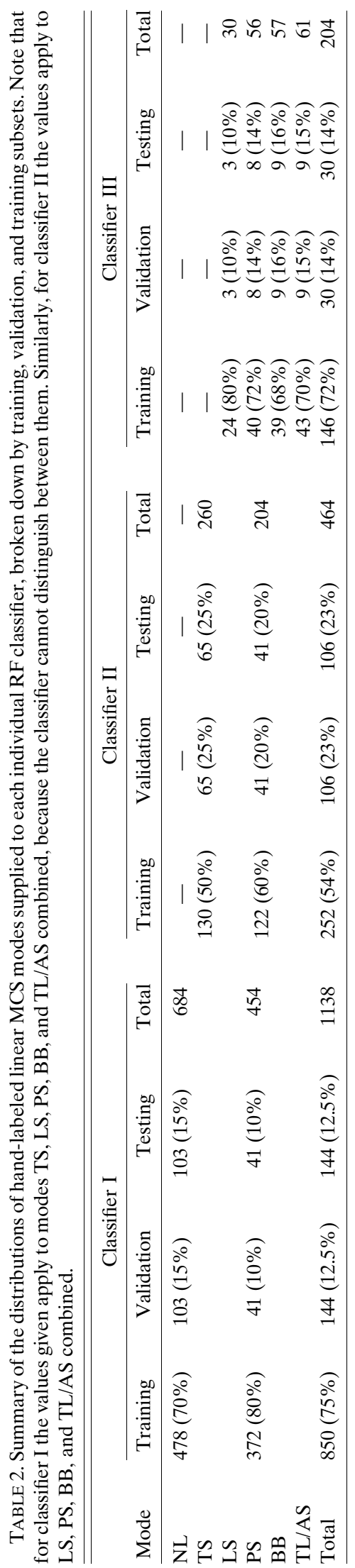

they are TS or the other linear types. Next, the systems that are predicted under the other linear categories from classifier II will be sent to classifier III to identify the exact linear mode they belong to. By combining the predicted results from all three classifiers, the number of systems belong to each mode can be determined.

Table 3 summarizes the precision and recall scores of all classifiers of each mode for the testing set and all-sample population. The overall performance is similar in each individual classifier with both precision and recall values falling between 0.83 and 0.87 on the test set and 0.89 and 0.96 on all data sample. The test set for ensemble classifiers combines the test sets from the individual classifiers, the duplicated sample, and the sample that has been used for training the classifier has been excluded (the sample from the validation set might be included). The ensemble RF classifier performs slightly worse than the individual classifier. This is expected as the false predictions are passed from classifier I all the way down to classifier III. Based on the ensemble classifier values from test set, the NL and TL/AS modes have higher precision scores than recall scores, indicating that more cases in these modes are misclassified than other modes, while it is the opposite for TS, LS, and BB modes.

To further evaluate whether the model can classify systems correctly, the confusion matrices, which are the heat maps of true versus predicted classification, are shown in Fig. 3. The counts along the major diagonal represent correct classifications, and off-diagonal counts are incorrect classifications. For the test set (upper panel), $\sim 13 \%$ of the NL systems are falsely classified as linear, and $\sim 15 \%$ of the linear systems are misclassified as NL systems in classifier I. For classifier II, the accuracy of TS mode identification is $\sim 10 \%$ higher than the other linear mode. Classifier III shows higher misclassification counts in the PS and TL/AS modes than the other two modes and the prediction accuracy is also relatively low for the LS mode. The low accuracy in determining LS systems could be attributed to its lower amount of training data. Again, the number of correct predictions of each linear mode is slightly lower in the ensemble classifier than each individual classifier.

For the performance of the ensemble classifier on the entire population (Fig. 3i), the NL systems are most frequently mislabeled as TS, followed by the BB and TL/AS modes. For predicted linear systems, the model shows some difficulty in distinguishing between TS and remaining linear modes, as high off-diagonal counts are found for the TS mode. Here, we also show the performance of using a single RFs classifier to classify each of the six modes in Table 3 (last column) and Fig. 3 (last column). This single classifier is also trained and validated following the procedures described above, with model tuning on the selected hyperparameters and predictors. The validation results of the test set indicate that the single classifier has difficulty in distinguishing the LS, PS, BB, and TL/AS systems from the NL and TS systems as almost all systems under other linear mode categories are misclassified as NL and TS modes. The number of correctly predicted systems under each mode is also lower than the ensemble classifier for the entire population.

The ensemble classifier is then applied to the mode classification for MCSs tracked during the period 2006-13. Figure 4 
TABLE 3. The precision and recall for the six modes for each individual RF classifier, the ensemble classifier, and the single classifier based on all hand-labeled MCSs. The left column under precision and recall represents the score calculated on the basis of the testing set, and the right column represents the score calculated using the all-sample population. The averages of precision and recall are calculated on the basis of the weight of each mode, which is determined by the number of MCSs that belong to that mode. Note that for classifier I the values given apply to modes TS, LS, PS, BB, and TL/AS combined, because the classifier cannot distinguish between them. Similarly, for classifier II the values apply to LS, PS, BB, and TL/AS combined.

\begin{tabular}{|c|c|c|c|c|c|c|c|c|c|c|c|c|c|c|c|c|c|c|c|c|}
\hline \multirow{3}{*}{$\frac{\text { Mode }}{\text { NL }}$} & \multicolumn{4}{|c|}{ Classifier I } & \multicolumn{4}{|c|}{ Classifier II } & \multicolumn{4}{|c|}{ Classifier III } & \multicolumn{4}{|c|}{ Ensemble } & \multicolumn{4}{|c|}{ Single classifier } \\
\hline & \multicolumn{2}{|c|}{ Precision } & \multicolumn{2}{|c|}{ Recall } & \multicolumn{2}{|c|}{ Precision } & \multicolumn{2}{|c|}{ Recall } & \multicolumn{2}{|c|}{ Precision } & \multicolumn{2}{|c|}{ Recall } & \multicolumn{2}{|c|}{ Precision } & \multicolumn{2}{|c|}{ Recall } & \multicolumn{2}{|c|}{ Precision } & \multicolumn{2}{|c|}{ Recall } \\
\hline & & 0.98 & & & - & - & - & - & - & - & - & - & 0.93 & 0.98 & & & 0.77 & 0.92 & 0.98 & 0.96 \\
\hline TS & & & & & & 0.89 & 0.89 & 0.92 & - & - & - & - & & 0.87 & & & & & & 0.88 \\
\hline$S$ & & & & & & & & & 0.75 & 0.90 & 1.00 & & & 0.82 & 0. & & .00 & & 0 & 0.80 \\
\hline PS & 0.78 & 0.94 & 0.85 & 0.97 & 082 & 089 & & & 0.73 & 0.81 & 1.00 & 0. & 0.63 & 0.76 & 0.63 & 0. & 0.00 & 0.95 & 0.00 & 0.70 \\
\hline תי & & & & & & & & & 0.88 & 0.96 & 0.78 & & 0.70 & 0.82 & 0.7 & & 0.67 & 0.9 & 0.22 & 0.75 \\
\hline$\Gamma \mathrm{L} / \mathrm{A}$ & & & & & & & & & 1. & 0. & 0.67 & & & 0.83 & 0.56 & & 0.00 & 1.00 & 0.00 & 0.69 \\
\hline Avg & 0.87 & 0.96 & 0.87 & 0.96 & 0.85 & 0.89 & 0.87 & 0.89 & 0.86 & 0.90 & 0.83 & 0.90 & 0.86 & 0.92 & 0.84 & 0.92 & 0.67 & 0.90 & 0.76 & 0.90 \\
\hline
\end{tabular}

compares the distribution of number of systems in each mode between the manually labeled ones and the model-predicted ones. The percentage of predicted systems under the NL mode $(61.6 \%)$ is slightly higher than the hand-labeled one $(59.6 \%)$, while for the TS mode the predicted sample $(22.1 \%)$ is almost identical to the hand-labeled one $(22.6 \%)$, which is likely related to the offset between the false positive and true negative errors associated with TS mode prediction as seen in Fig. 3. For the PS, BB, and TL/AS modes, the differences are $\sim 1 \%$, whereas LS systems account for a much smaller portion of the model outputs than the hand-labeled cases.

To further examine the model-prediction results, we randomly selected a system from each mode classified by the model, and the temporal evolution of their associated SL3D classifications is shown in Fig. 5. At the selected time steps, the SL3Ds from predicted NL, TS, PS, and BB systems (Figs. 5a,b,d,e) match their mode features very well. The predicted LS case is apparently an NL system and was misclassified by the model (Fig. 5c). The storm structure of the model-predicted TL/AS system (Fig. 5d) mimics a TS system, but the development of the convective line is located at the rear and bottom part of the system rather than along the entire stratiform region as seen in Figs. $5 b$ and $3 a$.

Although some uncertainties and misclassifications exist, the high accuracy ( $\sim 85 \%$ on the test set) indicates that the ensemble classifier is sufficiently accurate to be applied operationally to the long-term MCS morphology mode classification. The analyses performed in the following sections are based on both manually labeled and model-predicted systems for different modes.

\section{MCS characteristics associated with different modes}

In this section, the characteristics associated with different linear modes of MCSs and how these characteristics differ from
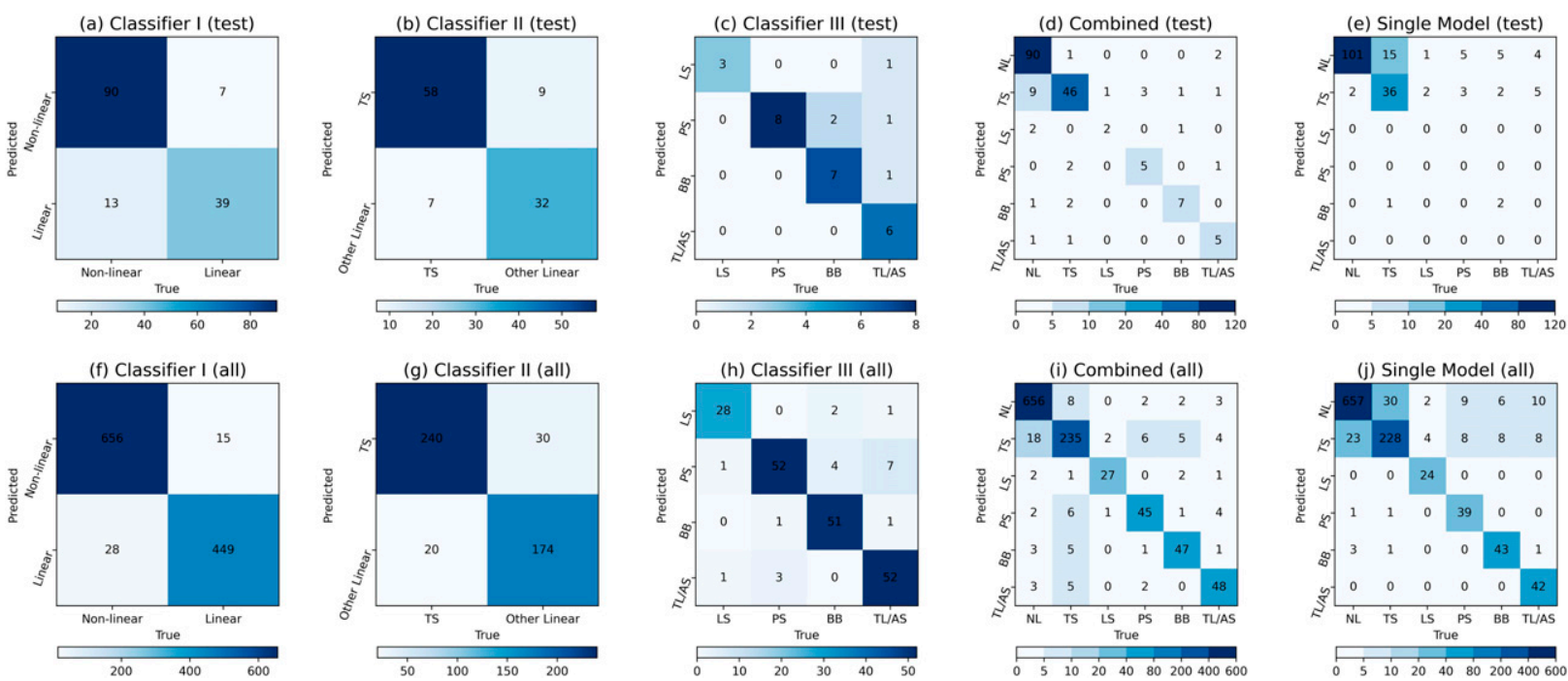

FIG. 3. Confusion matrix for each individual classifier, three classifiers combined, and single classifier, showing the the confusion matrix for (top) the test set and (bottom) the entire data population. The true mode label is depicted along the $x$ axis, and the predicted mode label is depicted along the $y$ axis, with cell shading indicating the count of the number of systems in the testing dataset having that pair of the true and predicted mode labels. 

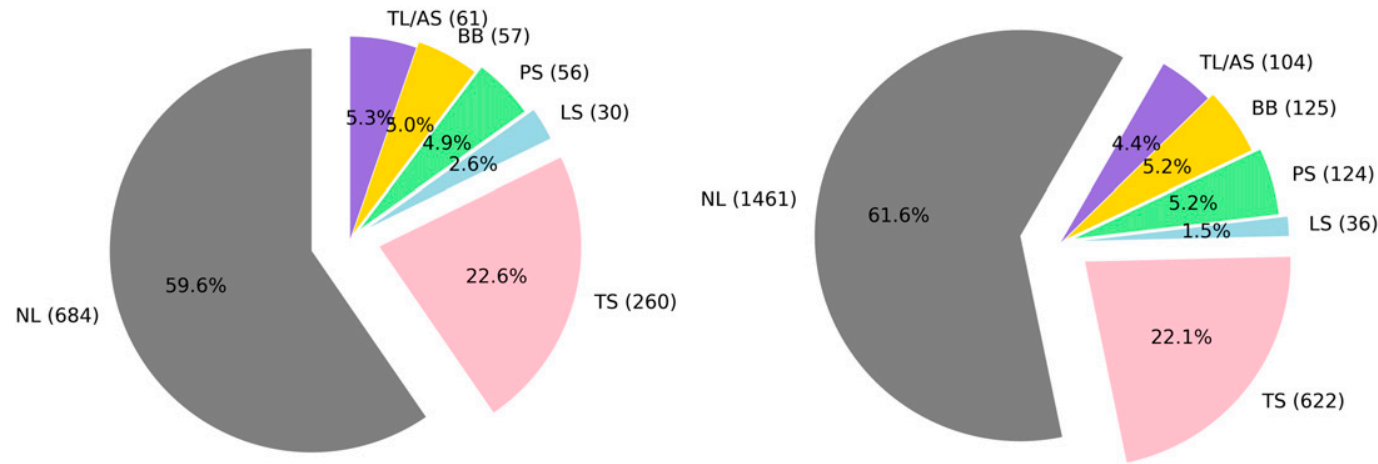

FIG. 4. Pie charts showing the distributions of (a) hand-labeled modes and (b) model-predicted modes.

each mode are examined over the central and eastern United States during a 13-yr period.

Figure 6 shows the interannual (March-October), monthly, and hourly variations of MCS occurrence. For interannual variability (Fig. 6a), the annual mean occurrence of linear MCSs is around 110, with the ratios of linear to NL ranging from 0.3 to 0.5 . The occurrence of linear MCSs also shows poor correlation with the occurrence of total or NL MCSs. The linear MCS number is found to be the lowest in 2012 and the highest in 2011. However, the total MCS number peaks in 2009 and dips in 2016. Because the production of linear system requires certain environmental and dynamical conditions (PJ00; SJ05), the interannual variations in large-scale circulation could alter the environments that are responsible for the production linear MCSs. For example, Cui et al. (2020b) found that the yearly MCS occurrence frequency and their precipitation properties in central and southern China are directly related to the intensity of a southwesterly low-level jet and midlevel westerly warm advection from the Tibetan Plateau during the East Asia monsoon season. More detailed analyses are needed to explain the interannual variability in linear MCSs. For seasonal variability (Fig. 6b), the occurrence frequencies of both linear and NL MCSs monotonically increase from March to June, and then decline to October. Higher ratios of linear to NL are observed from late spring to early summer. The diurnal variabilities of linear and NL systems show good agreement, with a higher probability of linear system occurring in the afternoon to sunset as indicated by higher ratios of linear to NL (Fig. 6c).

Figure 7 further illustrates the percentages of seasonal and diurnal occurrence frequency of five linear modes, some pattern shifts are observed relative to the sample number in Fig. 6 for some individual modes. For example, there is no obvious seasonable variation in PS mode, but there are clearly higher TS, LS, BB, and TL/AS occurrences during late spring and summer months. For the diurnal variation of convective initiation (CI), all six modes follow the overall pattern seen in Fig. 6c, with the CI most frequently occurring between 1400 and $1600 \mathrm{LT}$. These results have revealed that both the strong diurnal heating and local perturbations play important roles in triggering both NL and linear MCSs during the warm season
(Feng et al. 2019). A secondary peak of CI is also found in PS and TL/AS systems after sunset. The diurnal cycle of MCS genesis (Fig. 7c) shows that the genesis often occurs 3 or $4 \mathrm{~h}$ after the initiation time, with most systems reaching MCS criteria between 1800 and 1900 LT. A secondary peak of MCS genesis around midnight is found in all linear modes, indicating that the production of linear MCSs can also be enhanced by the nocturnal large-scale environments.

The initiation locations and spatial occurrences of MCSs in each mode are shown in Fig. 8. Each CI location is color-coded with its probability density, which is calculated based on the Gaussian kernel density estimation method described in Scott (1992). The spatial distribution of MCS occurrences is computed by counting the overlaps between the cloud coverages of all MCSs during their lifetimes. By combining the spatial distribution information from both CI locations and MCS occurrences, the development tendency of stratiform regions and movement associated with MCSs in each mode can be inferred. For instance, the systems in TS mode have a maximum CI density in Kansas/Nebraska, while the maximum of TS MCS occurrences is located in southern Iowa. This result indicates that TS MCSs have eastward movement and their propagation speeds are faster and/or their lifetime are longer than PS and $\mathrm{BB}$ systems. The northeastward displacement of the maximum is likely related to the development of a stratiform region to the northeast side of the system during its mature and dissipation stages, which is a feature commonly found in TS systems. The distribution of LS systems (Fig. 8b1) is relatively dispersed in the domain in comparison with the systems in other modes because of its limited sample size. The initiations of LS systems are primarily over the central Great Plains, and the displacement between the initiation density and occurrence maximum is smaller than those in TS mode, implying that LS systems generally move slower and/or have shorter lifetime than TS systems. For BB systems, the spatial distributions of CI locations and number of MCS occurrence are very similar to each other, which is expected due their slow movement resulting from the rear development of convective regions. The spatial distributions of TL/AS systems are similar to those in TS mode, except the maximum MCS occurrence appears on the east of 
(a1) NL SL3D at 2009/03/01 $13 Z$

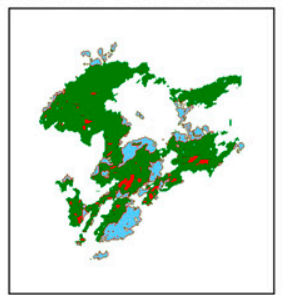

(b1) TS SL3D at 2011/07/18 $03 Z$

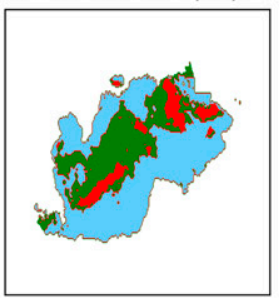

(c1) LS SL3D at 2007/05/23 $10 Z$

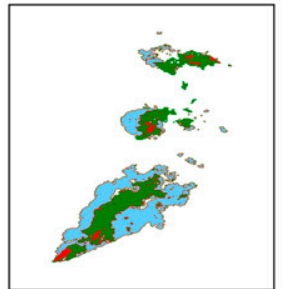

(d1) PS SL3D at 2011/07/09 00Z

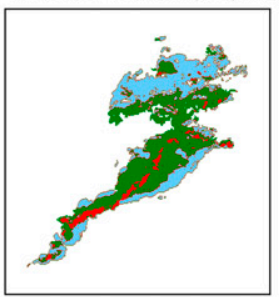

(e1) BB SL3D at 2006/07/18 $03 Z$

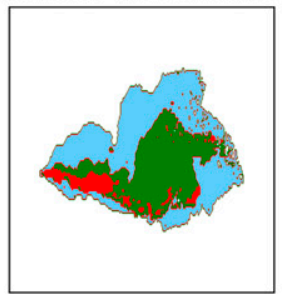

(f1) TL/AS SL3D at 2008/08/04 $10 Z$

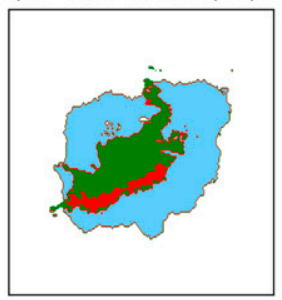

(a2) NL SL3D at 2009/03/01 $14 Z$

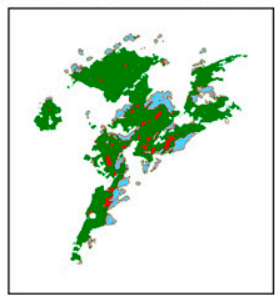

(b2) TS SL3D at 2011/07/18 04Z

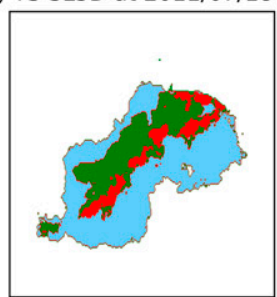

(c2) LS SL3D at 2007/05/23 $11 Z$

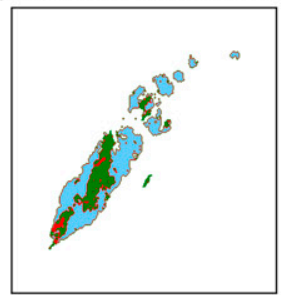

(d2) PS SL3D at 2011/07/09 012

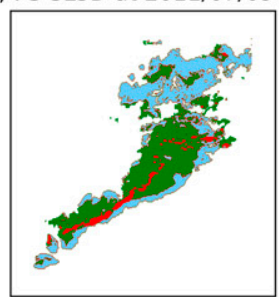

(e2) BB SL3D at 2006/07/18 04Z

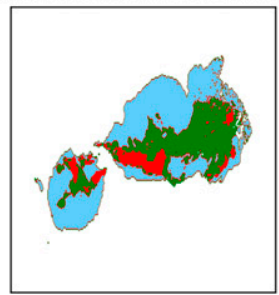

(f2) TL/AS SL3D at 2008/08/04 $11 Z$

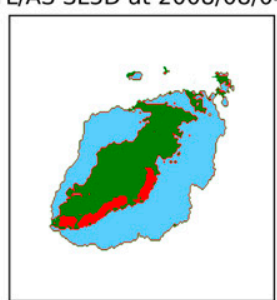

(c1) NL SL3D at 2009/03/01 15Z

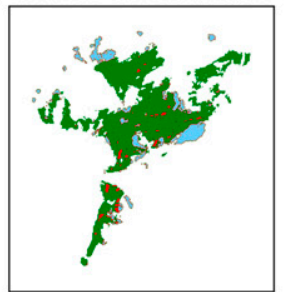

(b3) TS SL3D at 2011/07/18 05Z

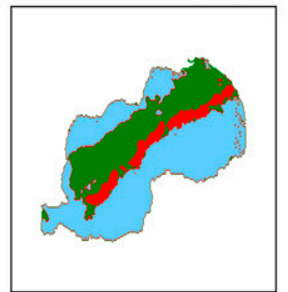

(c3) LS SL3D at 2007/05/23 $12 Z$

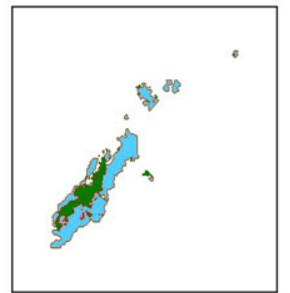

(d3) PS SL3D at 2011/07/09 02Z

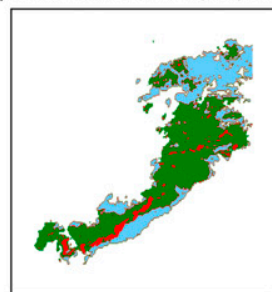

(e3) BB SL3D at 2006/07/18 05Z

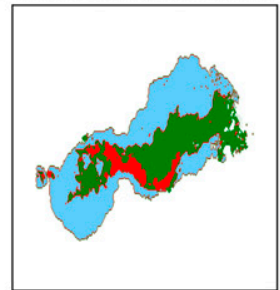

(f3) TL/AS SL3D at 2008/08/04 $12 Z$

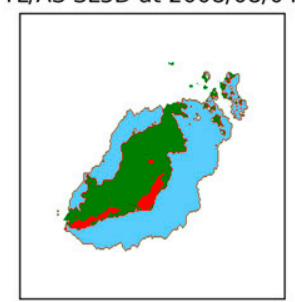

FIG. 5. Temporal evolution of SL3D classifications of randomly selected MCSs with model-predicted mode at (center) the times when systems' linearity features are the most apparent and left an hour (left) ahead and (right) after the selected time for (a1)-(a3) NL MCS; (b1)-(b3) TS MCS; (c1)-(c3) LS MCS; (d1)-(d3) PS MCS; (e1)-(e3) BB MCS; and (f1)-(f3) TL/AS MCS. 


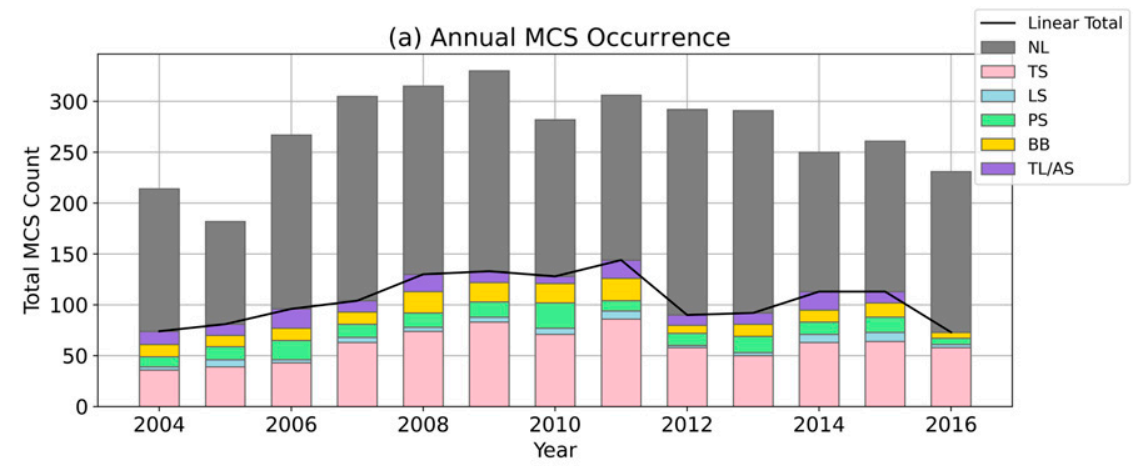

(b) Monthly MCS Occurrence

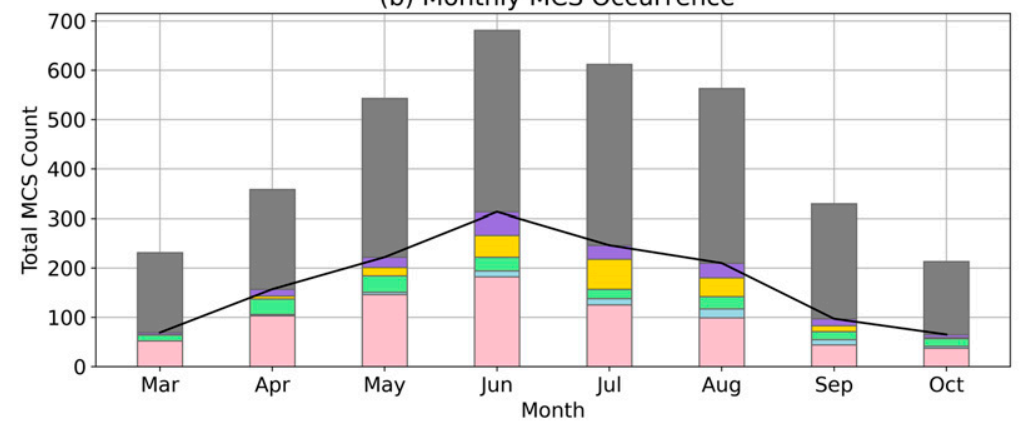

(c) Hourly MCS Occurrence

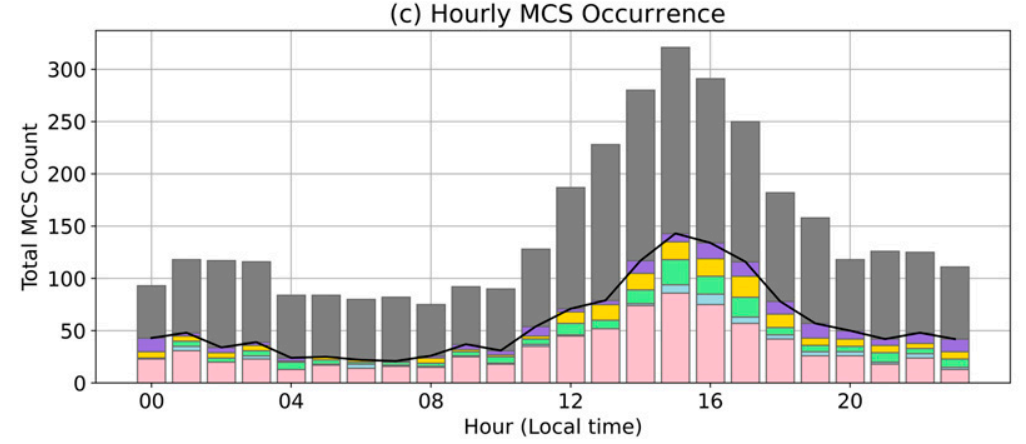

FIG. 6. The stacked histograms showing the (a) interannual (March-October), (b) monthly, and (c) hourly (the hour that the MCS was initiated) variations of MCS occurrences for the six selected modes.

the maximum CI density. This result suggests a west-to-east orientation for the stratiform region of TL/AS systems instead of a southwest-to-northeast orientation as seen in TS cases.

The MCS properties in terms of CCS lifetime, orientation, eccentricity, propagation speed, largest convective region major axis length, and PF area are compared between different modes. Here the orientation value is taken at the time when system linearity is the most apparent; the eccentricity, major axis length, and PF area values are calculated during the period when the system meets the MCS criteria defined in section $2 b$. The mean value of each variable is summarized in Table 4 and is also presented in the form of boxplots as shown in Fig. 9. Among all linear modes, the systems in the TS mode have the longest duration of $23.68 \mathrm{~h}$, while the systems in the BB mode have the shortest duration of $19.07 \mathrm{~h}$. Through MCS propagation speed and lifetime properties, the travel distance of a MCS can be inferred. Apparently, TS MCSs have the longest travel distance among all linear MCSs because of their longest lifespan and fastest propagation speed. This is consistent with the results in Fig. 8, such that the largest displacement between of CI location and MCS occurrence maximum is seen in TS MCSs. These characteristics of TS MCSs are expected because their initiations are often associated with fast-moving synoptic cold fronts (PJ00; Cui et al. 2019), resulting in a fastmoving speed of TS MCSs while providing a more favorable thermodynamic condition for sustaining the systems. The orientation of MCSs is expressed in degrees from north, and the $0^{\circ}$ and $90^{\circ}$ values represent that the systems have north-tosouth and west-to-east orientations, respectively. Therefore, TS, LS, and PS MCSs generally have a southwest-to-northeast orientation, while most of the BB and TL/AS MCSs are westto-east oriented, which agrees with the findings in PJ00 and 
(a) Monthly MCS Occurrence

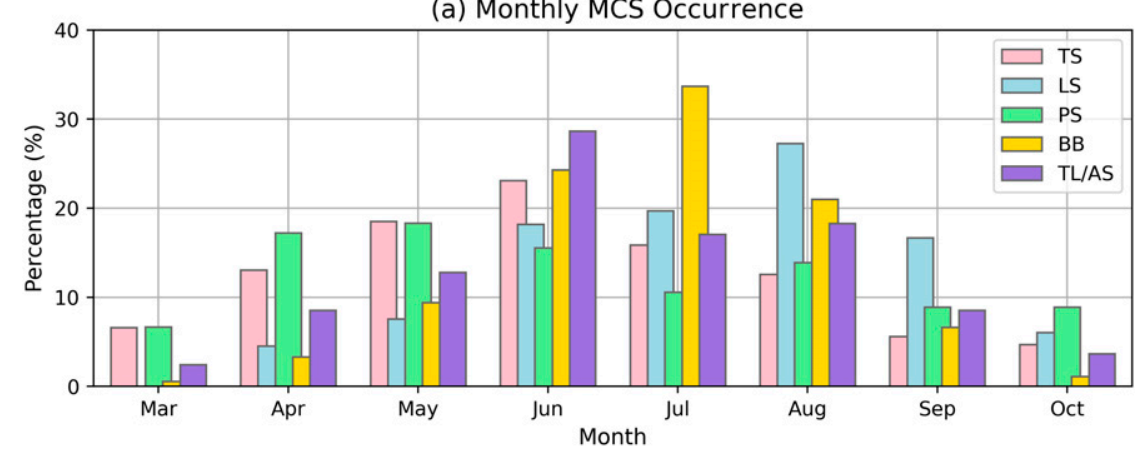

(b) MCS Initiation Time

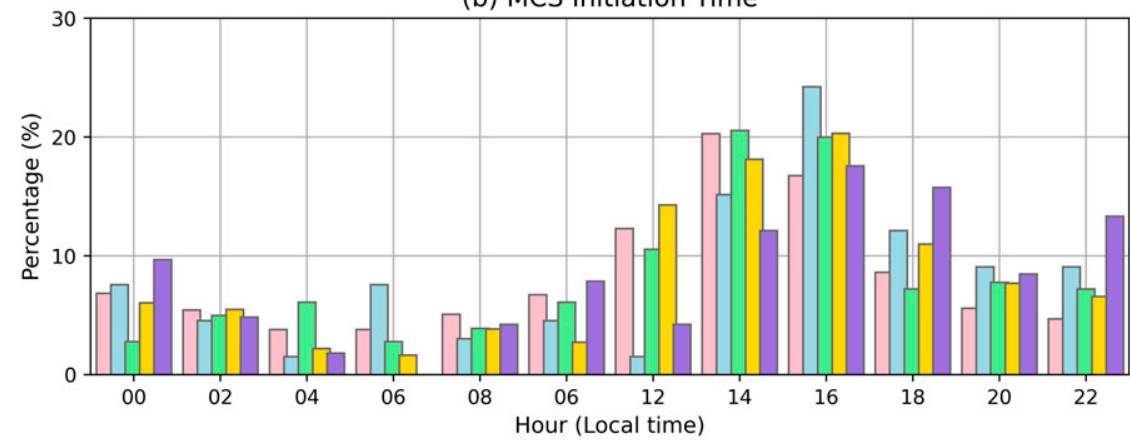

(c) MCS Genesis Time

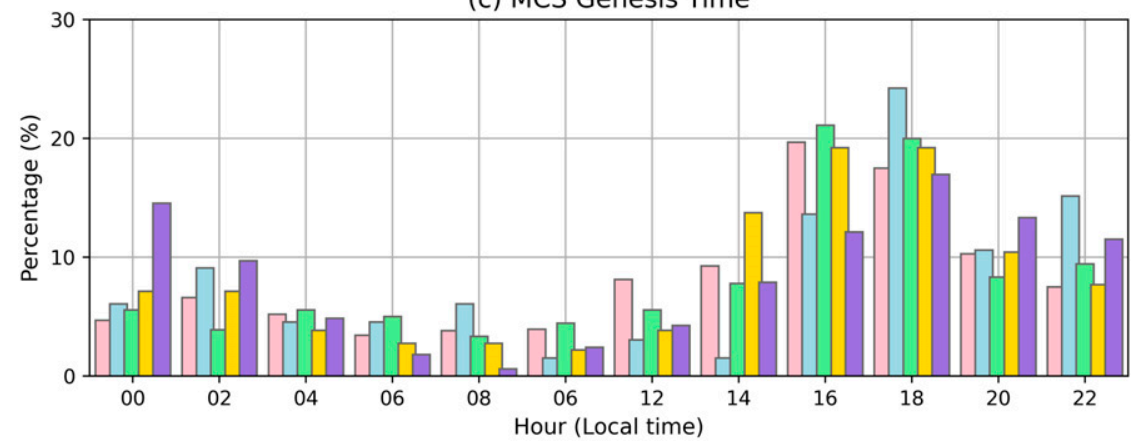

FIG. 7. Histograms showing (a) the percentages of the MCSs from the five selected modes occurred at the given month, and their corresponding (b) initiation and (c) genesis occurrences at the given local time.

SJ05. Based on the CCS eccentricity values, PS systems have the most asymmetric shape, which is probably related to the extensive development of line-parallel stratiform regions. TS systems have the largest $\mathrm{CC}$ major axis length and PF area while LS systems have the smallest length and size among all linear types.

Figure 10 shows the $\mathrm{PF}$ rain rates associated with each mode, and their corresponding rain rates for the stratiform (Fig. 10b) and convective (Fig. 10c) regions. The grid accumulated precipitation through MCS lifetime is also calculated to assess the flooding potential associated with the different types of systems (Fig. 10d). Their mean values can also be found in Table 4. The total (stratiform + convective) rain rate is the highest in $\mathrm{BB}$ systems $\left(3.27 \mathrm{~mm} \mathrm{~h}^{-1}\right)$, followed by LS systems $\left(3.13 \mathrm{~mm} \mathrm{~h}^{-1}\right)$. The mean rain rate of NL systems is $2.84 \mathrm{~mm} \mathrm{~h}^{-1}$, which is higher than TS, PS, and BB systems. The CC rain rates are roughly 2 times the SR rain rates in all modes, and the rain rate variations are also much larger than their SR counterparts. BB systems have the highest rain rate values for both $\mathrm{SR}\left(2.93 \mathrm{~mm} \mathrm{~h}^{-1}\right)$ and CC $\left(5.46 \mathrm{~mm} \mathrm{~h}^{-1}\right)$ regions, followed by LS systems. As SJ05 pointed out, BB and TL/AS modes are often associated with extreme rain events. For BB systems, this is expected because of their high precipitation rates and slow movement, which can easily produce high volumes of localized precipitation in a short amount of time. This is further confirmed by the highest grid accumulated precipitation of $\mathrm{BB}$ systems with a mean value of $144.51 \mathrm{~mm}$, which is significantly higher than the other linear systems. The results here also suggest that LS systems may have higher potential for producing extreme rain events than TL/AS systems for the same reason, because LS systems have the second highest grid accumulated precipitation although their lifetime is the shortest among all linear modes. However, because of the low 
(a1) TS Initiation Locations
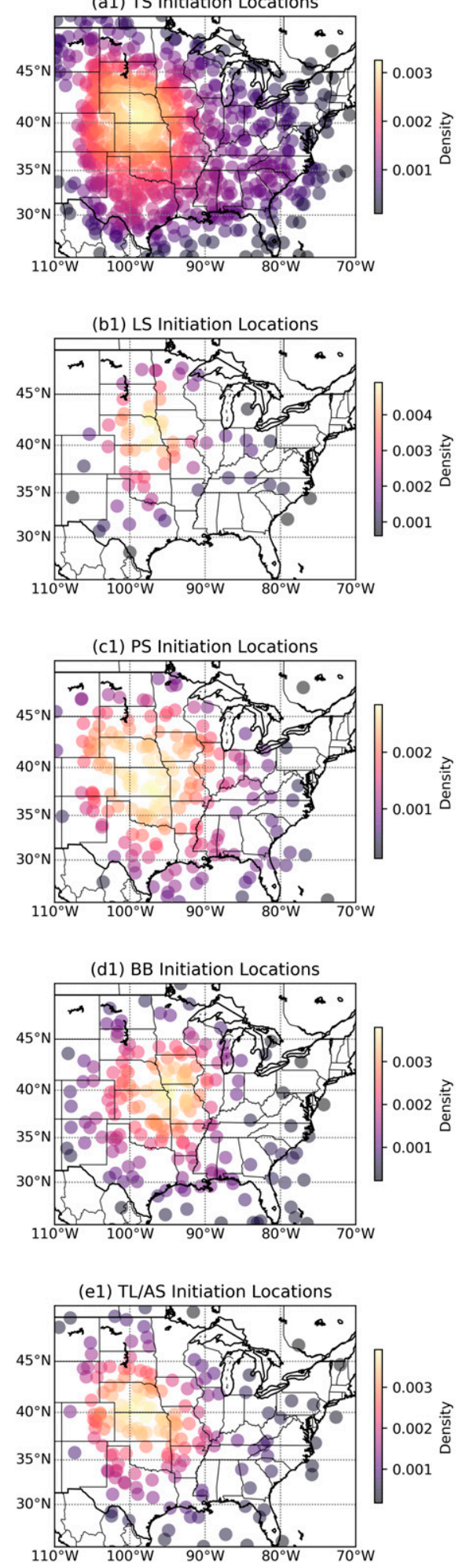

(a2) TS Spatial Occurrence
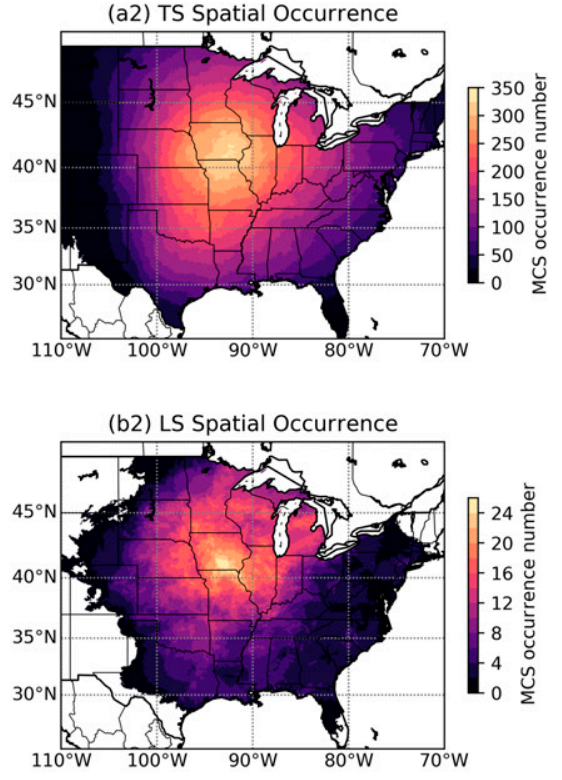

(c2) PS Spatial Occurrence

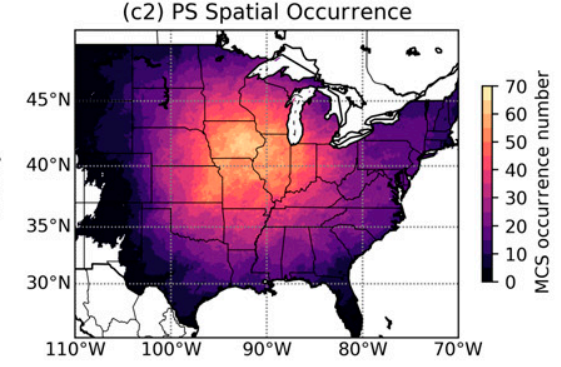

(d2) BB Spatial Occurrence

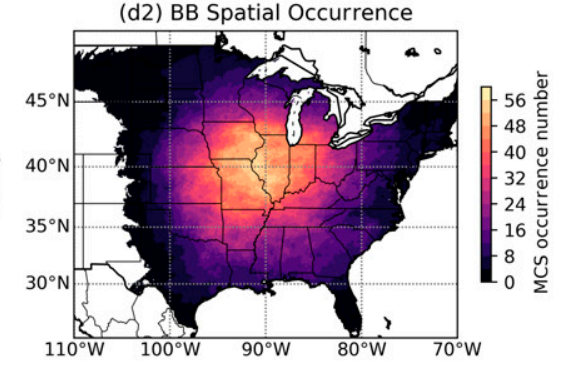

(e2) TL/AS Spatial Occurrence

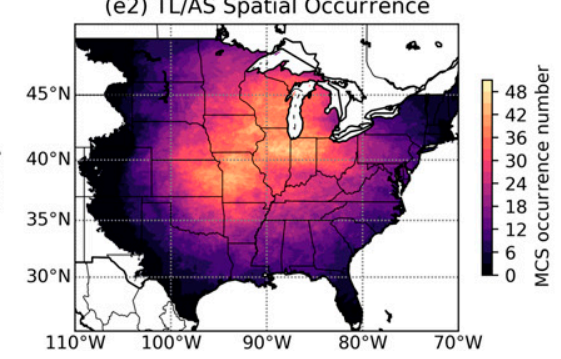

FIG. 8. (a1)-(e1) The spatial distributions of MCS convective initiation locations, colorcoded with probability density, and (a2)-(e2) the spatial distributions of MCS occurrence number of the five linear modes (from March to October 2004-16). 
TABLE 4. Mean values of variables of interest shown in Fig. 9 for the six modes. The maximum value of each variable is shown in boldface type.

\begin{tabular}{|c|c|c|c|c|c|c|}
\hline Variables & NL & TS & LS & PS & $\mathrm{BB}$ & TL/AS \\
\hline Lifetime (h) & 20.34 & 23.68 & 20.85 & 20.50 & 19.07 & 21.13 \\
\hline Orientation $\left({ }^{\circ}\right)$ & 79.29 & 63.14 & 65.64 & 61.10 & 87.14 & 85.53 \\
\hline Eccentricity & 0.80 & 0.80 & 0.79 & 0.85 & 0.83 & 0.82 \\
\hline Speed $\left(\mathrm{m} \mathrm{s}^{-1}\right)$ & 21.57 & 26.34 & 20.69 & 26.00 & 18.29 & 20.92 \\
\hline $\begin{array}{l}\text { Largest convective region major axis } \\
\text { length }(\mathrm{km})\end{array}$ & 107.43 & 173.47 & 148.11 & 163.41 & 167.16 & 151.94 \\
\hline $\mathrm{PF}$ area $\left(\mathrm{km}^{2} \times 1000\right)$ & 38.06 & 71.69 & 37.90 & 60.72 & 43.78 & 41.44 \\
\hline Rain rate $\left(\mathrm{mm} \mathrm{h}^{-1}\right)$ & 2.84 & 2.80 & 3.13 & 2.80 & 3.27 & 2.84 \\
\hline $\mathrm{SR}$ rain rate $\left(\mathrm{mm} \mathrm{h}^{-1}\right)$ & 2.61 & 2.69 & 3.06 & 2.62 & 2.93 & 2.66 \\
\hline $\mathrm{CC}$ rain rate $\left(\mathrm{mm} \mathrm{h}^{-1}\right)$ & 4.67 & 4.40 & 5.16 & 4.55 & 5.46 & 4.53 \\
\hline Grid accumulated precipitation (mm) & 116.21 & 122.92 & 133.58 & 121.45 & 144.51 & 122.13 \\
\hline
\end{tabular}

occurrence frequency of LS systems, no comprehensive analysis was conducted in SJ05 to study LS systems' associated properties.

\section{Environmental conditions associated with different MCS modes}

The environmental conditions associated with MCSs in different modes are analyzed and compared in this section to better understand the key environmental factors that are responsible for the production of certain organization of linear system. The vertical wind field and the large-scale environments at CI and MCS genesis locations of each classified MCS are analyzed based on ERA5 analysis fields.

The mid- and upper-tropospheric storm-relative winds play important roles in determining the organization of MCSs (PJ00; Cui et al. 2019). The wind directly influences the advection of ice hydrometers and therefore the development of stratiform region (Herzegh and Hobbs 1980). The upper panel (a) Lifetime

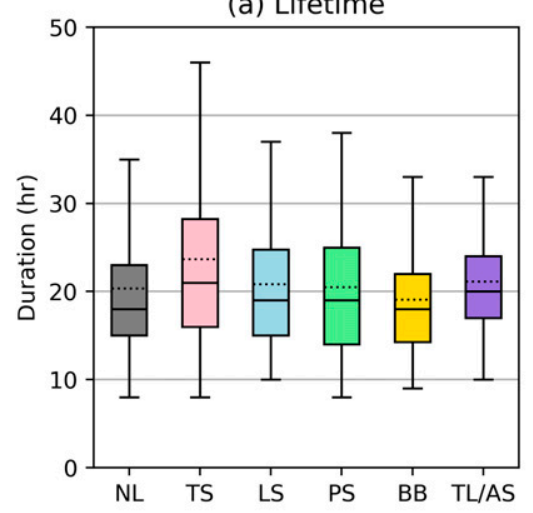

(d) Propagation Speed

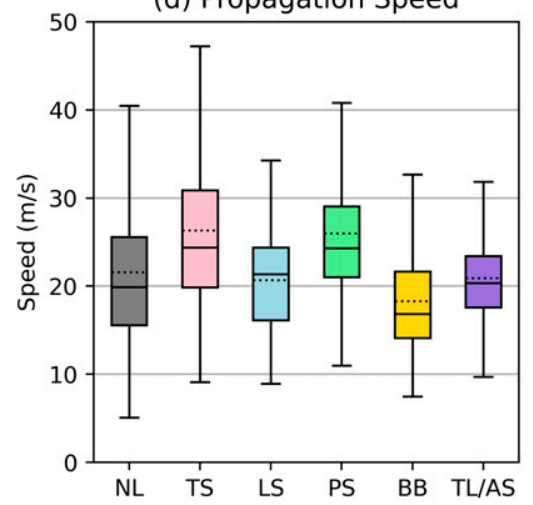

(b) Orientation

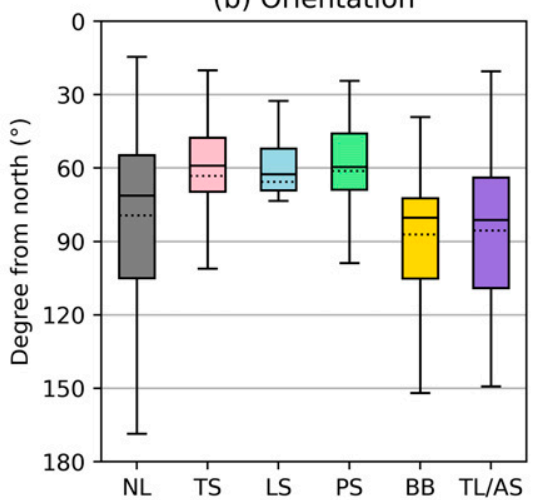

(e) Largest CC Major Axis Length

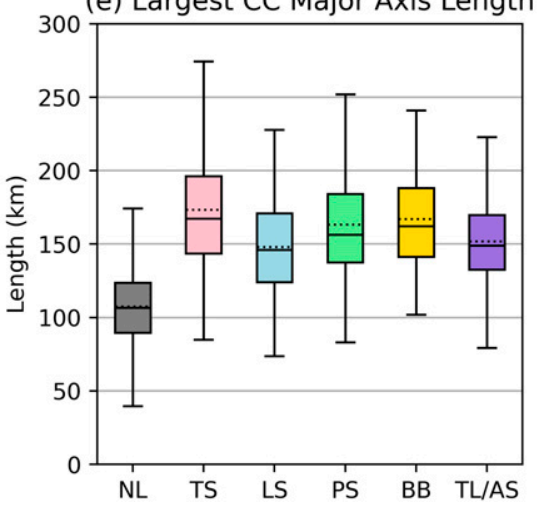

(c) CCS Eccentricity

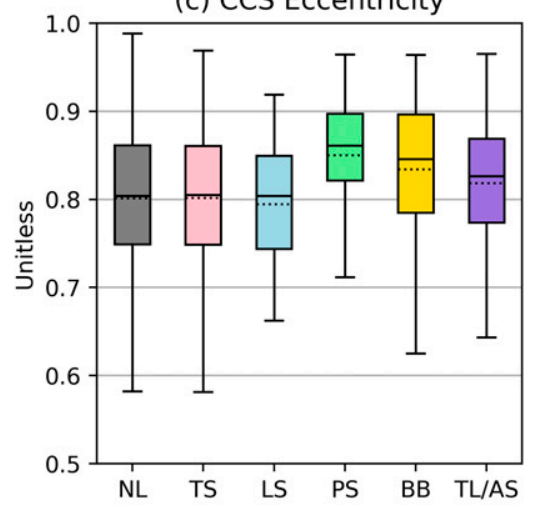

(f) PF Area

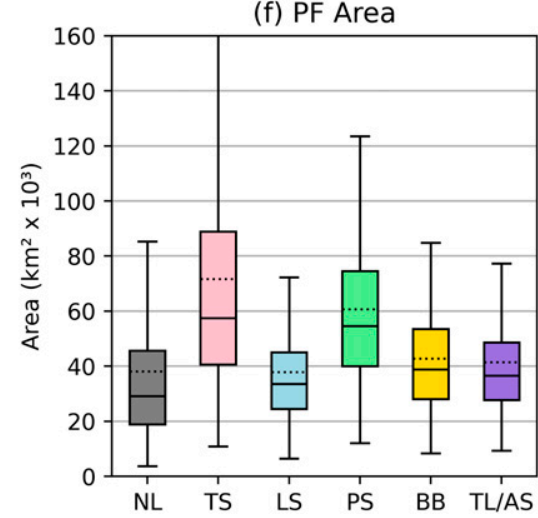

FIG. 9. Boxplots of the six selected variables associated with MCSs of the six modes; the variables are (a) lifetime, (b) orientation of the system, (c) CCS eccentricity, (d) propagation speed, (e) the largest convective region major axis length, and (f) PF area. The solid line in the box represents the median value and the dashed line in the box represents the mean value of the dataset for constructing the boxplot. 

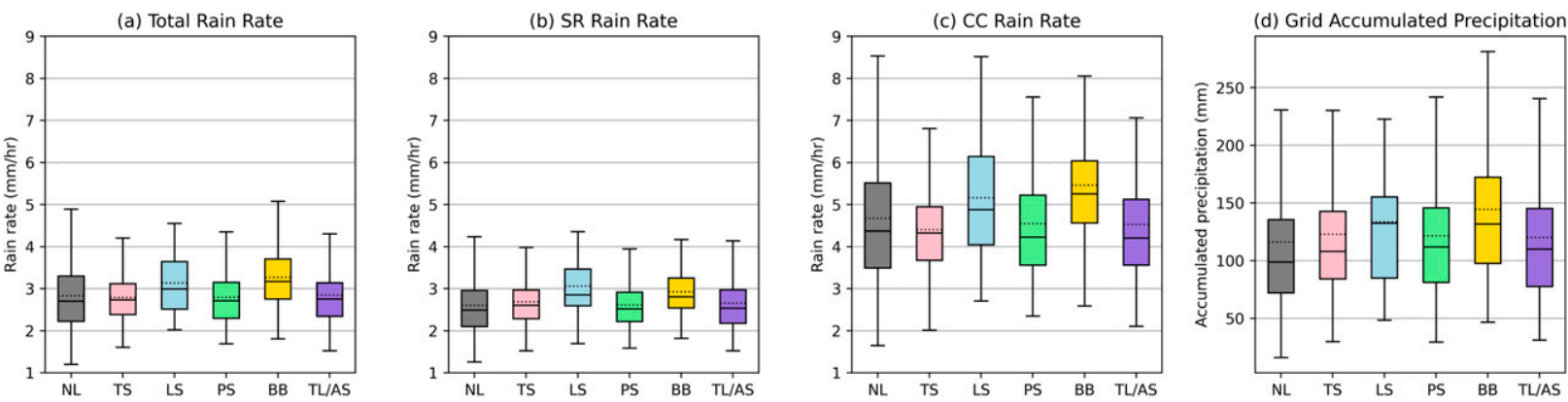

FIG. 10. As in Fig. 9, but for (a) total (stratiform + convective) rain rate, (b) stratiform rain rate, (c) convective rain rate, and (d) grid accumulated precipitation of PFs for the six modes.

of Fig. 11 shows the vertical distributions of zonal and meridional wind for the five linear modes. The wind profiles are similar at CI and MCS genesis times (not shown), but large discrepancies are found between different modes in terms of the wind speed and wind direction. The systems in TS mode are characterized by southwesterly winds in the lower troposphere, and the wind becomes westerly at middle and upper levels. LS systems experience very weak winds at lower levels and northwesterly winds aloft. The vertical wind shear is relatively weak in comparison with the other linear systems. The PS systems experience southwesterly wind at all levels. The vertical wind distributions are similar in BB and TL/AS systems; both modes are characterized by southwesterly winds at lower levels and westerly winds with very a small northerly component aloft, except that the wind magnitudes are much larger in TL/AS systems at all levels. A low-level jet $(\sim 950 \mathrm{hPa})$ is found in TS, $\mathrm{PS}$, and BB systems, and a much stronger jet at $200 \mathrm{hPa}$ is found in PS and TL/AS systems.

We further examine the storm-relative wind (Kerr and Darkow 1996) at different levels to understand the impact of environmental flow on the development of stratiform region in each mode. The storm-relative wind is computed by subtracting the storm movement speed from the environmental wind speed at different levels. The wind speeds and directions at 975 , $800,600,350$, and $200 \mathrm{hPa}$ (approximately $0.3,2,4,8,12 \mathrm{~km}$, respectively) are chosen for calculating the storm-relative winds and the results are shown in Figs. 11a2-11e2. The systems with different modes defined in PJ00 usually have a
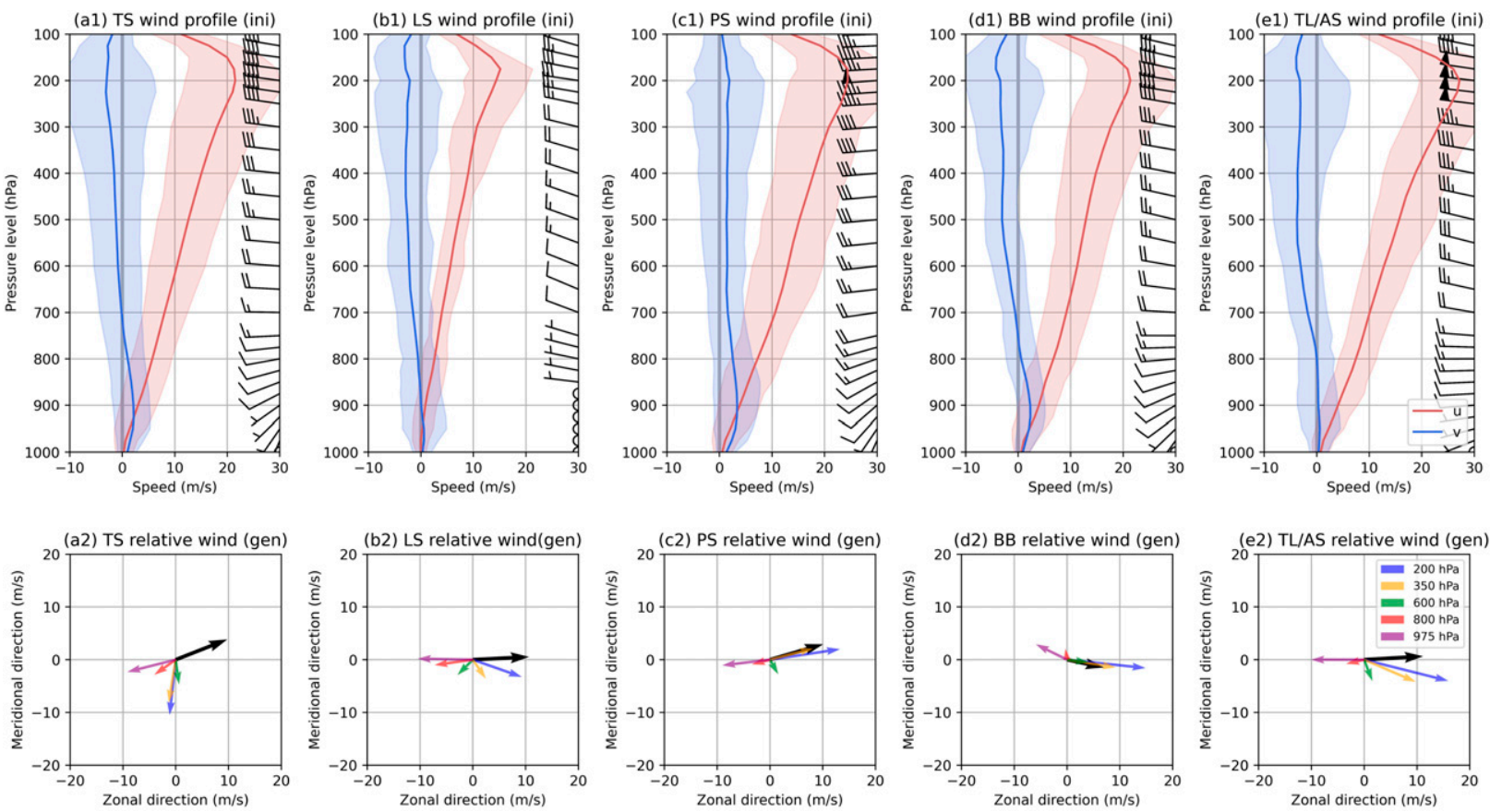

FIG. 11. (a1)-(e1) The vertical wind profiles at MCS initiation (ini) locations of the five linear modes; the red line represents the zonal wind and the blue line represents the meridional wind. The shaded area represents the range from the 25th to 75 th percentile of the wind speed at the given pressure level. (a2)-(e2) The MCS propagation speed and direction (black arrow) and associated storm-relative winds at 975-, 800-, 600-, 350-, and 200-hPa pressure levels of the five linear modes at MCS genesis (gen) locations. 

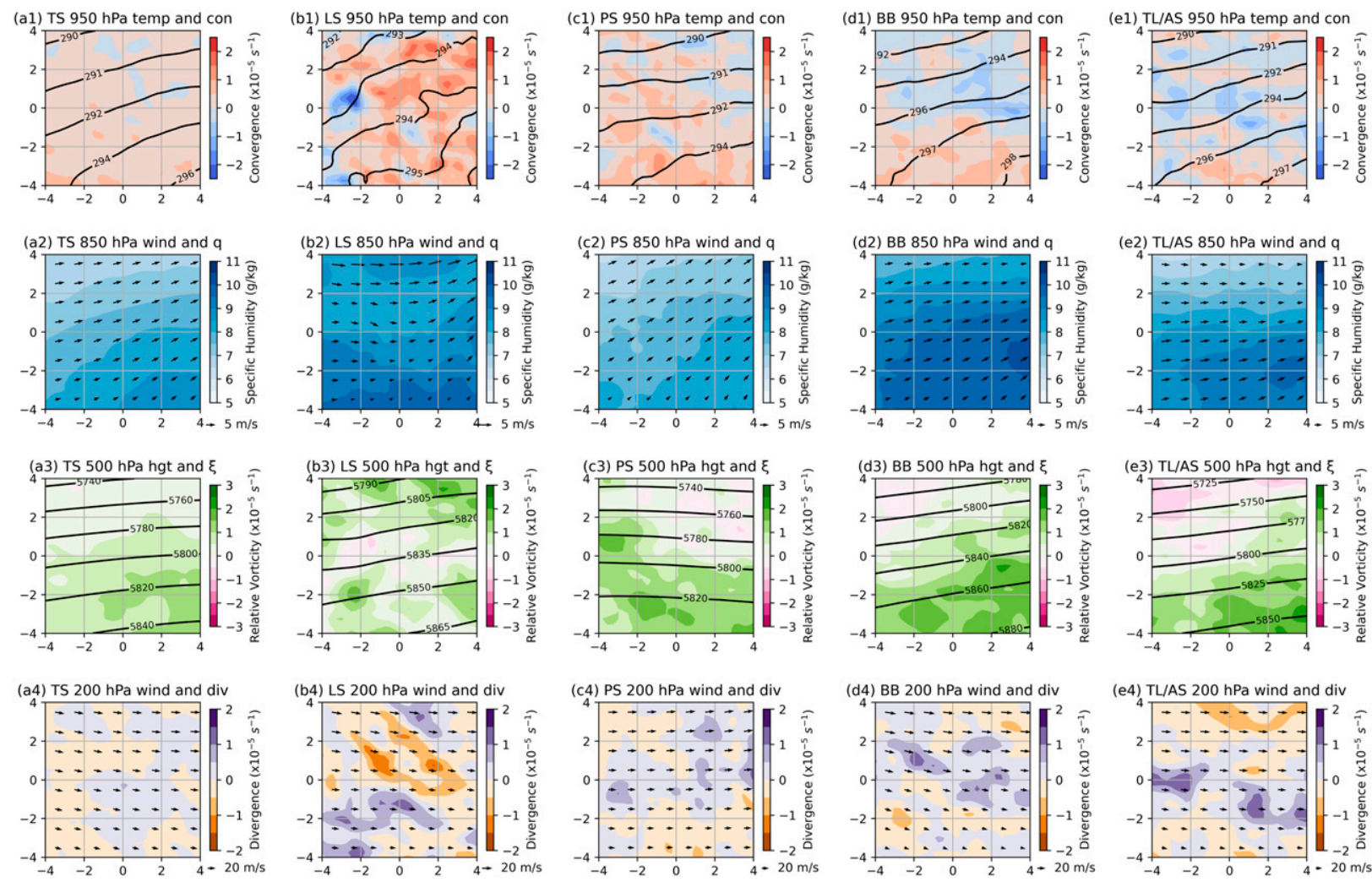

FIG. 12. The atmospheric mean states normalized within an $8^{\circ}$ box around the convective initiation locations of the five linear modes for (a1)-(e1) 950-hPa temperature and convergence, (a2)-(e2) 850-hPa wind and specific humidity, (a3)-(e3) 500-hPa geopotential height and relative vorticity, and (a4)-(e4) 200-hPa wind and divergence. Coordinate (0, 0) represents the system's initiation location.

southwest-to-northeast orientation with a line-perpendicular movement, which is also confirmed in Fig. 9. Therefore, from this perspective, the TS systems experience slightly front-torear storm-relative wind at low- and midlevels and convective line-parallel winds aloft. For LS systems, the storm-relative flow shifts from front-to-rear line-parallel to rear-to-front lineperpendicular from lower to upper levels. The rear-to-front storm-relative flows at middle and upper levels associated with LS systems are consistent with the forward advection of hydrometeors, resulting in the forward development of stratiform rain regions. Except an observed near-surface front-to-rear wind, PS systems exhibit rear-to-front line-parallel winds at all levels, such that the advection of hydrometeors is largely along the line.

The climatology analysis of storm-relative winds associated with TS, PS, and LS systems is consistent with the findings in PJ00, although only 88 linear MCSs were examined in their study, as opposed to 1391 linear MCSs in this study. Because the systems in these two modes consist of a west-to-east orientation and line-parallel movement, the systems in BB and TL/AS modes exhibit similar storm-relative winds at all levels, except that relative flows associated with TL/AS systems are much deeper than those with BB systems. Hence, the stormrelative flow is front-to-rear near the surface and switches to rear-to-front and line-parallel in the middle and upper troposphere in both modes. The near-surface and upper-level storm-relative flows have similar magnitudes but in opposite directions, which could result in a quasi-stationary movement of BB systems. The simultaneous eastward propagations of convective and stratiform regions of TL/AS MCSs could be attributed to the strong, rear-to-front line-parallel flows in the upper troposphere. The strength and the direction of the winds from 600 to $200 \mathrm{hPa}$ are significantly different among the six linear modes in this study, suggesting that the middle- and uppertropospheric storm-relative wind field is of primary importance in determining the organizational mode of a linear system.

To further investigate the environmental factors that may lead to distinguishable MCS characteristics in each mode, the synoptic patterns associated with CI are analyzed and shown in Fig. 12. The mean values of environmental variables are calculated by compositing values from each case for an $8^{\circ} \times 8^{\circ}$ box centered on the location of CI. Atmospheric parameters including lower-tropospheric convergence and specific humidity, midtropospheric relative vorticity (RV), and upper-tropospheric divergence are examined. The initiation of TS systems occurs with low-level moisture convergence, with southwesterly winds of $\sim 8 \mathrm{~m} \mathrm{~s}^{-1}$ over the normalized domain. The initiation of LS systems is associated with strong convergence at $950 \mathrm{hPa}$ but a relatively weak horizontal wind at $850 \mathrm{hPa}$. The availability of moisture is also low at the CI point relative to the surrounding area, which is dramatically different from the other linear modes. The initiation of PS systems is characterized by southwesterly LLJ, with wind speeds of $\sim 10 \mathrm{~m} \mathrm{~s}^{-1}$ at the CI point. 
TABLE 5. Most-unstable convective available potential energy (MUCAPE) and most-unstable convective inhibition (MUCIN) for the six modes at convective initiation (ini; first two rows) and MCS genesis (gen; third and fourth rows) locations and times.

\begin{tabular}{lcccccc}
\hline \hline & NL & TS & LS & PS & BB & TL/AS \\
\hline MUCAPE (ini) & 853.80 & 1053.35 & 955.66 & 865.18 & 1048.16 & 853.90 \\
MUCIN (ini) & 36.64 & 37.77 & 42.68 & 29.39 & 37.88 & 31.97 \\
MUCAPE (gen) & 860.24 & 1126.84 & 975.10 & 743.32 & 1057.74 & 821.36 \\
MUCIN (gen) & 36.52 & 34.35 & 18.68 & 21.01 & 23.67 & 19.70 \\
\hline
\end{tabular}

Similar to TS and PS systems, the initiation of BB systems also occurs at the low-level moisture convergence zone, but the 950$\mathrm{hPa}$ temperature is higher in $\mathrm{BB}$ systems than the others. The availability of moisture associated with BB systems is also significantly higher than the other linear systems. These features suggest that the occurrence of $\mathrm{BB}$ systems is associated with a quasi-stationary warm front. The low-level environment associated with TL/AS systems is characterized by westerly wind convergence, and larger north-south specific humidity and temperature gradients $\left(7 \mathrm{~g} \mathrm{~kg}^{-1}\right.$ difference in specific humidity and 7-K difference in temperature from south to north boundaries) relative to the other linear systems.

For 500-hPa environments, strong cyclonic vorticity advection occurred over the normalized domain for TS mode, implying a quasigeostrophic ascent. Meanwhile, the initiations of LS, PS, BB, and TL/AS systems are located at the transition zone between the cyclonic and anticyclonic vorticities, indicating the existence of directional wind shear except that the locations of positive and negative vorticities associated with LS systems are reversed relative to PS and TL/AS systems. From combing the 500-hPa geopotential height information, it can be inferred that the initiation of LS systems is located east of a ridge, while the initiations of other linear systems occur ahead of a midtropospheric trough. The initiations of TS, PS, and TL/AS systems are characterized by a westerly wind field at 200-hPa level and much higher wind speeds are found in PS and TL/AS systems. For LS and BB systems, northwesterly winds are seen across the normalized domain. Positive divergence is found at the initiation locations of TS, PS, BB, and TL/AS systems. These atmospheric variables are also examined at MCS genesis time and location, and they exhibit similar spatial patterns to those shown in Fig. 12, except with some small discrepancies. These discrepancies include a slight increase of moisture availability at lower levels and an intensification of midlevel ascent from CI to MCS genesis in all modes (not shown).

Most unstable convective available potential energy (MUCAPE) and most unstable convective inhibition (MUCIN) are computed from ERA5 variables for each MCS, and the mean values of each mode are summarized in Table 5 . The mean MUCAPE values imply that TS and BB MCSs occur in air masses with more conditional instability, while TL/AS cases occur in air masses with the least instability. The mean CAPE value of NL systems is similar to TL/AS systems, suggesting that the vertical motion associated with linear systems is not necessarily stronger than NL systems. The formations of LS, PS, and TL/AS are more of a combination of relatively weaker lift but a stronger sheared environment (Figs. 11 and 12b3,c3,e3).
The environmental conditions normalized at CI locations between the linear and NL systems are also compared to understand which environmental factors are more important in creating the linear organization (Fig. 13). At $950 \mathrm{hPa}$, except for $\mathrm{BB}$ and TL/AS systems, the vertical motions associated with linear MCSs are stronger than NL MCSs at the CI location. The NL systems tend to form at a more uniform low-level environment, as larger gradients of convergence values are found in association with linear systems. Larger low-level temperature gradients relative to NL systems are also observed in TS, PS, and TL/AS systems across the domain. Besides TS and PS systems, the low-level moisture availability is higher in linear systems than in NL systems, and the positive difference is substantially large in BB systems (up to $3 \mathrm{~g} \mathrm{~kg}^{-1}$ ). In terms of wind field, the southwest component of the wind is found to be stronger in TS and PS systems than NL systems, which could be related to the enhanced Great Plains LLJ overnight. For BB and TL/AS systems, the westerly component of the wind is stronger than NL systems, and the wind speed difference can be as large as $4 \mathrm{~m} \mathrm{~s}^{-1}$. Differing from the other linear systems that an enhanced westerly wind is observed, LS systems experience northerly and northeasterly winds across the domain. The positive difference in relative vorticity at $500 \mathrm{hPa}$ indicates that the midlevel ascent is stronger in linear systems. At $200 \mathrm{hPa}$, linear systems are characterized by stronger divergence than the NL systems.

To briefly summarize the findings in this section, 1) the vertical wind shear and storm-relative flow in different linear MCS modes exhibit large variations; 2) the vertical directional wind shear is the largest in LS systems, and the change in wind magnitude with height is the largest in TL/AS systems; and 3) the organizational mode of a linear MCS is largely determined by the middle- and upper-tropospheric storm-relative flow, which directly affects the advection of ice hydrometeors and thus the expansion of the associated stratiform clouds.

The environmental conditions associated with the initiation of linear MCSs are significantly different between each mode. For instance, TS and BB systems occur at a more conditionally unstable environment, while LS, PS, and TL/AS MCSs occur in more stable air masses with stronger vertical shear. The precipitation intensity associated with systems in different modes is correlated to the low-level moisture availability, as BB systems have higher precipitation rates and higher moisture availability at $850 \mathrm{hPa}$ than the systems in other linear modes. In contrast to NL systems, linear systems form in an environment with stronger ascending motion and sharper temperature and moisture gradients. The precipitation rates of NL systems are slightly higher than TS and PS systems, which could be due 

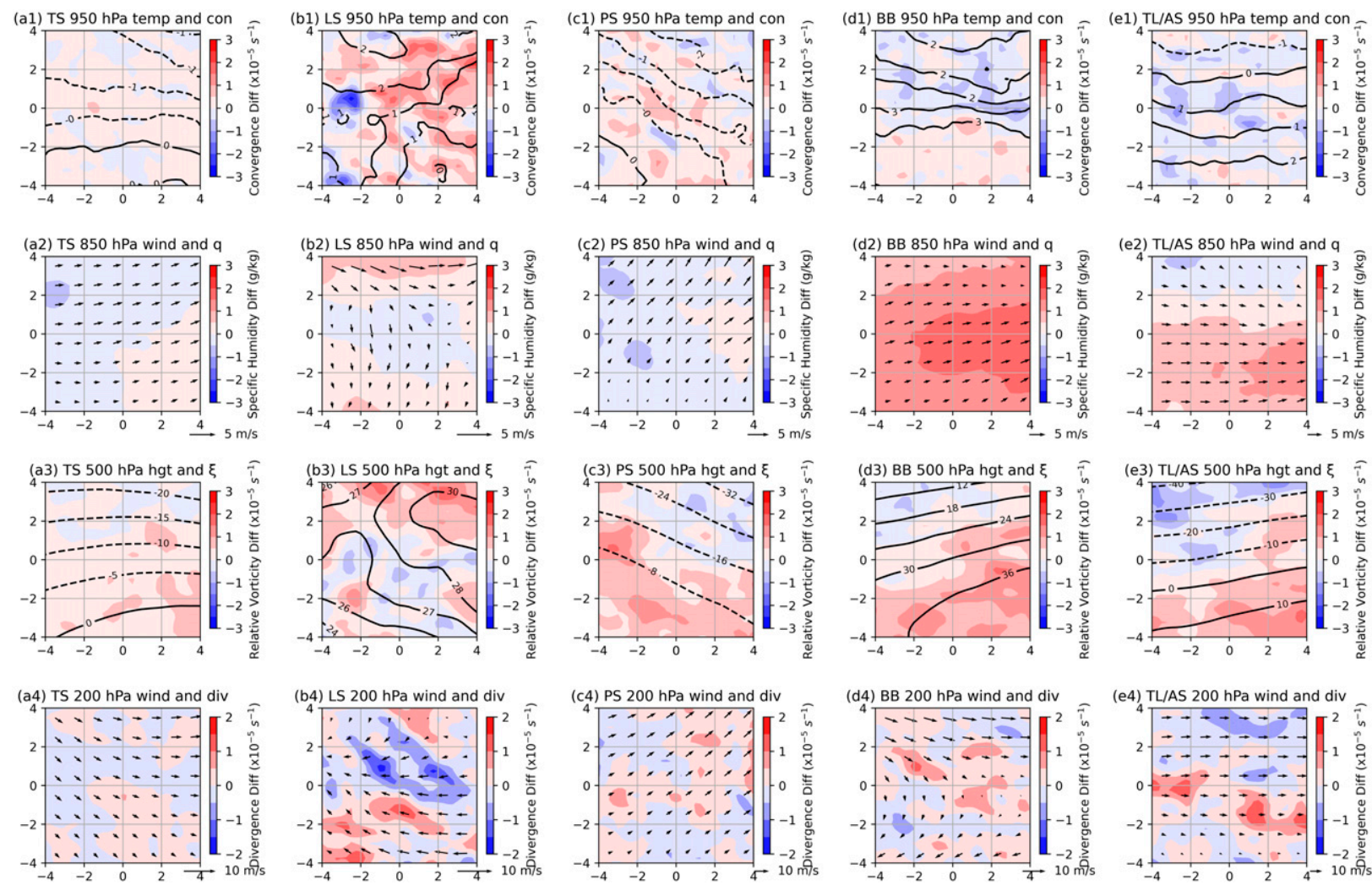

FIG. 13. As in Fig. 12, but for the differences between the five linear modes and the nonlinear mode (linear minus nonlinear).

to the higher moisture availability associated with NL systems. However, NL MCSs' grid accumulated precipitation is less than all linear MCSs and less likely to produce flooding events.

\section{Summary and conclusions}

A machine-learning model that is based on random forests has been developed and used to generate a climatology of linear MCS morphology over the central and eastern United States according to the modes defined in PJ00 and SJ05. The model is developed based on a large set of morphological parameters from a 13-yr radar-based warm season MCS dataset, in which five years of MCSs (1148 cases) are manually identified for training and testing purposes, and the other eight years of MCSs (2388 cases) are used for model implantation. The statistical evaluation shows that the model does have misclassification issues in predicting the minority MCS mode due to the limited training sample size, but the overall accuracy of $85 \%$ is acceptable for linear MCS morphology classification from a long-term dataset.

On the basis of the model-predicted classes, the linear MCSs account for roughly $40 \%$ of all MCSs, and more than half of the linear MCSs fall under TS mode, while the least fall under the LS mode. The occurrence number of linear MCSs shows large annual variation. On average, 113 linear MCSs occur annually during the warm season, with the most events occurring in 2011, and the least occurring in 2016, which does not follow the pattern of total MCS occurrence number. Linear MCSs occur more frequently from May to August and the proportion of linear to nonlinear MCSs is also larger during this period. The peak month is slightly different for each linear mode. The diurnal cycle of CI peaks in the afternoon and MCS genesis peaks after sunset.

In comparing the characteristics associated with given linear modes of MCSs, it is seen that TS MCSs have the longest duration, the fastest propagation speed, and the largest cold cloud shied, while LS and BB MCSs rank as the bottom two in terms of these properties. This result is probably due to TS MCSs' frequent relationship to synoptic cold fronts. The LS and BB MCSs typically move much slowly and have higher precipitation rates than the other modes, which results in more extreme rainfall and flash flooding events.

This study also examined the lower-, middle-, and uppertropospheric environmental conditions associated with MCSs' initiation and genesis. Several environmental factors are more important in determining the MCSs' characteristics than others, such as higher moisture availability at the lower troposphere and higher precipitation rate. The organizational mode of the linear MCSs is largely determined by the middle- and uppertropospheric storm-relative winds, at which levels the advection of ice hydrometeors occurs the most frequently. The accurate representation of these factors may be important for simulating linear MCSs in regional models.

The results presented in this study provide an overview of the climatology of linear MCSs in the central and eastern 
United States by incorporating a machine-learning algorithm, namely the random forest. Note that, in additional to the RFs, convolution neural networks (CNNs), one of the deep-learning algorithms, have also been used to develop automated classification algorithms of linear MCS morphology and have been compared with the RF-based classifier presented in this study. Although multiple parameter-tuning processes are involved, the model developed from RFs still outperforms the model developed by CNNs, as also pointed out by Thielen (2018), where both algorithms were used for the determination of the nine detailed convective cluster types. The MCS-associated characteristics and environmental conditions analyzed based on the model-predicted mode in this study affirm some of the findings from earlier studies. However, the innovation of this study is offering new discoveries and advancing a different methodological detection template to provide a robust and objective categorization of these events. The future applications of the methods and baseline climatology presented in this study include understanding the response of interannual variability of linear MCSs to large-scale environmental patterns and investigating the future evolution of these events based on high-resolution climate model simulations, as the linear MCS population may change in a warming climate.

Acknowledgments. This research was supported by the Climate Model Development and Validation (CMDV) program funded by the Office of Biological and Environmental Research (BER) in the U.S. Department of Energy (DOE) Office of Science under Grant DE-SC0017015 at The University of Arizona. Doctor Zhe Feng at the Pacific Northwest National Laboratory (PNNL) was supported by the DOE Office of Science BER as part of the Regional and Global Modeling and Analysis program through the Water Cycle and Climate Extremes Modeling (WACCEM) scientific focus area. PNNL is operated for the U.S. DOE by Battelle Memorial Institute under contract DE-AC05-76RL01830. The MCS dataset is obtained, with permission, from the DOE Atmospheric Radiation Measurement (ARM) data archive (https://doi.org/ 10.5439/1571643). The ERA5 reanalysis was obtained online (https://rda.ucar.edu/\#!lfd?nb=y\&b=proj\&v=ECWMF\% 20ERA5\%20Reanalysis). The paper was improved by the helpful suggestions of Mr. Jianfeng He at Virginia Polytechnic Institute and State University and two anonymous reviewers.

\section{REFERENCES}

Ashley, W. S., A. M. Haberlie, and J. Strohm, 2019: A climatology of quasi-linear convective systems and their hazards in the United States. Wea. Forecasting, 34, 1605-1631, https://doi.org/ 10.1175/WAF-D-19-0014.1.

Baldwin, M. E., J. S. Kain, and S. Lakshmivarahan, 2005: Development of an automated classification procedure for rainfall systems. Mon. Wea. Rev., 133, 844-862, https://doi.org/ 10.1175/MWR2892.1.

Bowman, K. P., and C. R. Homeyer, 2017: GridRad-Threedimensional gridded NEXRAD WSR-88D radar data. Research Data Archive at the National Center for Atmospheric Research Computational and Information Systems Laboratory, https:// doi.org/10.5065/D6NK3CR7.
Cui, W., X. Dong, B. Xi, J. Fan, J. Tian, J. Wang, and T. M. McHardy, 2019: Understanding ice cloud-precipitation properties of three modes of mesoscale convective systems during PECAN. J. Geophys. Res., 124, 4121-4140, https://doi.org/ 10.1029/2019JD030330.

,,,$--- Z$ Z Feng, and J. Fan, 2020a: Can the GPM IMERG Final product accurately represent MCSs' precipitation characteristics over the central and eastern United States? J. Hydrometeor., 21, 39-57, https://doi.org/10.1175/JHM-D19-0123.1.

$\ldots, \ldots, \ldots$, and M. Liu, 2020b: Cloud and precipitation properties of MCSs along the Meiyu frontal zone in central and southern China and their associated large-scale environments. J. Geophys. Res. Atmos., 125, e2019JD031601, https:// doi.org/10.1029/2019JD031601.

Feng, Z., and Coauthors, 2018: Structure and evolution of mesoscale convective systems: Sensitivity to cloud microphysics in convection-permitting simulations over the United States. J. Adv. Model. Earth Syst., 10, 1470-1494, https://doi.org/ 10.1029/2018MS001305.

—_, and Coauthors, 2019: Spatiotemporal characteristics and large-scale environments of mesoscale convective systems east of the Rocky Mountains. J. Climate, 32, 7303-7328, https:// doi.org/10.1175/JCLI-D-19-0137.1.

Fritsch, J. M., R. J. Kane, and C. R. Chelius, 1986: The contribution of mesoscale convective weather systems to the warmseason precipitation in the United States. J. Appl. Meteor., 25, 1333-1345, https://doi.org/10.1175/1520-0450(1986)025<1333: TCOMCW $>2.0 . \mathrm{CO} ; 2$.

Gagne, D. J., II, A. McGovern, and J. Brotzge, 2009: Classification of convective areas using decision trees. J. Atmos. Oceanic Technol., 26, 1341-1353, https://doi.org/10.1175/2008JTECHA1205.1.

$\longrightarrow,-$ J. B. Basara, and R. A. Brown, 2017: Storm-based probabilistic hail forecasting with machine learning applied to convection-allowing ensembles. Wea. Forecasting, 32, 18191840, https://doi.org/10.1175/WAF-D-17-0010.1.

- S. E. Haupt, D. W. Nychka, and G. Thompson, 2019: Interpretable deep learning for spatial analysis of severe hailstorms. Mon. Wea. Rev., 147, 2827-2845, https://doi.org/ 10.1175/MWR-D-18-0316.1.

Gallus, W. A., N. A. Snook, and E. V. Johnson, 2008: Spring and summer severe weather reports over the Midwest as a function of convective mode: A preliminary study. Wea. Forecasting, 23, 101-113, https://doi.org/10.1175/2007WAF2006120.1.

Guillot, E. M., T. M. Smith, V. Lakshmanan, K. L. Elmore, D. W. Burgess, and G. J. Stumpf, 2008: Tornado and severe thunderstorm warning forecast skill and its relationship to storm type. Preprints, 24th Conf. on Interactive Information Processing Systems for Meteorology, Oceanography, and Hydrology, New Orleans, LA, Amer. Meteor. Soc., 4A.3, http://ams.confex.com/ ams/pdfpapers/132244.pdf.

Haberlie, A. M., and W. S. Ashley, 2018: A method for identifying midlatitude mesoscale convective systems in radar mosaics. Part I: Segmentation and classification. J. Appl. Meteor. Climatol., 57, 1575-1598, https://doi.org/10.1175/JAMC-D-170293.1.

Herman, G. R., and R. S. Schumacher, 2018: Money doesn't grow on trees, but forecasts do: Forecasting extreme precipitation with random forests. Mon. Wea. Rev., 146, 1571-1600, https:// doi.org/10.1175/MWR-D-17-0250.1.

Hersbach, H., and Coauthors, 2020: The ERA5 global reanalysis. Quart. J. Roy. Meteor. Soc., 146, 1999-2049, https://doi.org/ 10.1002/qj.3803. 
Herzegh, P. H., and P. V. Hobbs, 1980: The mesoscale and microscale structure and organization of clouds and precipitation in mid-latitude cyclones. Part II: Warm frontal clouds. J. Atmos. Sci., 37, 597-611, https://doi.org/10.1175/ 1520-0469(1980)037<0597:TMAMSA >2.0.CO;2.

Houze, R. A., Jr., 2004: Mesoscale convective systems. Rev. Geophys., 42, RG4003, https://doi.org/10.1029/2004RG000150.

_ 2019: 100 years of research on mesoscale convective systems. A Century of Progress in Atmospheric and Related Sciences: Celebrating the American Meteorological Society Centennial, Meteor. Monogr., No. 59, Amer. Meteor. Soc., 17.1-17.54, https://doi.org/10.1175/AMSMONOGRAPHS-D-18-0001.1.

Janowiak, J. E., R. J. Joyce, and Y. Yarosh, 2001: A real-time global half-hourly pixel-resolution infrared dataset and its applications. Bull. Amer. Meteor. Soc., 82, 205-217, https://doi.org/ 10.1175/1520-0477(2001)082<0205:ARTGHH > 2.3.CO;2.

Jirak, I. L., and W. R. Cotton, 2007: Observational analysis of the predictability of mesoscale convective systems. Wea. Forecasting, 22, 813-838, https://doi.org/10.1175/WAF1012.1.

Kerr, B. W., and G. L. Darkow, 1996: Storm-relative winds and helicity in the tornadic thunderstorm environment. Wea. Forecasting, 11, 489-505, https://doi.org/10.1175/1520-0434(1996) $011<0489:$ SRWAHI $>2.0 . \mathrm{CO} ; 2$.

Lin, Y., and K. E. Mitchell, 2005: The NCEP stage II/ IV hourly precipitation analyses: Development and applications. Preprints, 19th Conf. on Hydrology, San Diego, CA, Amer. Meteor. Soc., 1.2., http://ams.confex.com/ams/pdfpapers/ 83847. pdf.

McGovern, A., K. L. Elmore, D. J. Gagne, S. E. Haupt, C. D. Karstens, R. Lagerquist, T. Smith, and J. K. Williams, 2017: Using artificial intelligence to improve real-time decisionmaking for high-impact weather. Bull. Amer. Meteor. Soc., 98, 2073-2090, https://doi.org/10.1175/BAMS-D-16-0123.1.

Nesbitt, S. W., R. Cifelli, and S. A. Rutledge, 2006: Storm morphology and rainfall characteristics of TRMM precipitation features. Mon. Wea. Rev., 134, 2702-2721, https://doi.org/ 10.1175/MWR3200.1.

Parker, M. D., and R. H. Johnson, 2000: Organizational modes of midlatitude mesoscale convective systems. Mon. Wea.
Rev., 128, 3413-3436, https://doi.org/10.1175/1520-0493(2001) 129<3413:OMOMMC $>2.0$.CO;2.

$\longrightarrow$, and - 2004: Structures and dynamics of quasi-2D mesoscale convective systems. J. Atmos. Sci., 61, 545-567, https://doi.org/ 10.1175/1520-0469(2004)061<0545:SADOQM>2.0.CO;2.

Pedregosa, F., and Coauthors, 2011: Scikitlearn: Machine learning in Python. J. Mach. Learn. Res., 12, 2825-2830, https://www.jmlr. org/papers/volume12/pedregosa11a/pedregosa11a.pdf.

Peters, J. M., and R. S. Schumacher, 2016: Dynamics governing a simulated mesoscale convective system with a training convective line. J. Atmos. Sci., 73, 2643-2664, https://doi.org/ 10.1175/JAS-D-15-0199.1.

Pettet, C. R., and R. H. Johnson, 2003: Airflow and precipitation structure of two leading stratiform mesoscale convective systems determined from operational datasets. Wea. Forecasting, 18, 685-699, https://doi.org/10.1175/1520-0434(2003)018<0685: AAPSOT $>2.0 . \mathrm{CO} ; 2$.

Schumacher, R. S., and R. H. Johnson, 2005: Organization and environmental properties of extreme-rain-producing mesoscale convective systems. Mon. Wea. Rev., 133, 961-976, https://doi.org/10.1175/MWR2899.1.

— and - 2006: Characteristics of extreme U.S. rain events during 1999-2003. Wea. Forecasting, 21, 69-85, https://doi.org/ 10.1175/WAF900.1.

Scott, D. W., 1992: Multivariate Density Estimation: Theory, Practice, and Visualization. John Wiley and Sons, 317 pp.

Starzec, M., C. R. Homeyer, and G. L. Mullendore, 2017: Storm Labeling in Three Dimensions (SL3D): A volumetric radar echo and dual-polarization updraft classification algorithm. Mon. Wea. Rev., 145, 1127-1145, https://doi.org/10.1175/MWRD-16-0089.1.

Thielen, J. E., 2018: Comparison of machine learning techniques for convective morphology classification from radar imagery. B.A. thesis, Iowa State University, 28 pp., https://lib.dr. iastate.edu/mteor_stheses/38.

Wang, X., C. Cui, W. Cui, and Y. Shi, 2014: Modes of mesoscale convective system organization during Meiyu season over the Yangtze River Basin. J. Meteor. Res., 28, 111-126, https:// doi.org/10.1007/s13351-014-0108-4. 